\title{
Conventional synthesis of perovskite structured LaTixFe1-x03: A comprehensive evaluation on phase formation, opto-magnetic, and dielectrical properties
}

\section{Ramesh Kumar Raji}

Anna University Chennai

Vishista Kurapati ( $\square$ raovishista@gmail.com )

Anna University Chennai

Tholkappiyan Ramachandran

United Arab Emirates University Main Library

M Muralidharan

University of Madras

R Suriakarthick

University of Madras

M Dhilip

SRM University

\section{Fathalla Hamed}

United Arab Emirates University Main Library

\section{Research Article}

Keywords: LaFeO3 perovskites, Conventional solid-state reaction, Rietveld refinement, Optical bandgap, photoluminescence, dielectric and magnetic behaviour

Posted Date: July 21st, 2020

DOI: https://doi.org/10.21203/rs.3.rs-44211/v1

License: (9) This work is licensed under a Creative Commons Attribution 4.0 International License. Read Full License

Version of Record: A version of this preprint was published at International Journal of Materials Research on September 1st, 2021. See the published version at https://doi.org/10.1515/ijmr-2020-8162. 


\section{Abstract}

In the current study, we report a comprehensive evaluation of the microstructures, optical, dielectric and magnetic traits of Ti-substituted perovskite structured lanthanum ferrite with chemical compositions $\mathrm{LaTi}_{\mathrm{x}} \mathrm{Fe}_{1-\mathrm{x}} \mathrm{O}_{3}(\mathrm{x}=0,0.05,0.15,0.25)$. X-ray diffraction with Rietveld refinement and Raman analysis confirmed that both pure and Ti-substituted $\mathrm{LaFeO}_{3}$ maintained single-phase orthorhombic phase with Pbnm symmetry. Fourier transform infrared spectroscopy (FTIR) studies revealed the information about the positions of the ions and their bonds within the lattice structure of the $\mathrm{LaFeO}_{3}$. The spherical shaped morphology of all products was confirmed by SEM. The quantitative chemical composition and their distribution were confirmed by EDAX and mapping. The UV-Vis spectroscopic studies showed an excitonic absorption edge at $590 \mathrm{~nm}$ is ascribed to the electronic transition from $\mathrm{O}_{2 \mathrm{p}} \rightarrow \mathrm{Fe}_{3 \mathrm{~d}}$. Optical band gap (Eg) values were assessed by applying Tauc schemes, showed that Eg values are in a narrow range $(1.85-2.02 \mathrm{eV})$. The dielectric properties such as, dielectric constant $\left(\varepsilon^{\prime}\right)$, dielectric loss $(\tan \delta)$ was examined by varying with temperature and frequency. The magnetic results revealed weak ferromagnetic nature trait at $300 \mathrm{~K}$. The variation in Ms (saturation magnetization), $\mathrm{Hc}$ (coercivity) and $\mathrm{Mr}$ (remanence) values were observed with increasing Ti substitution level.

\section{Introduction}

Lanthanum based perovskite oxides are the important class of material widely studied for their fascinating physical properties and variety of applications in vast field [1]. Lanthanum orthoferrite$\mathrm{LaFeO}_{3}$ has been utilized in a wide range of applications such as magnetic memory devices, sensors, hard disk drives, transducers, electrolytes and electrodes in solid oxide fuel cells [2-5]. The $\mathrm{ABO}_{3}$-type of $\mathrm{LaFeO}_{3}$ compound exhibit an orthorhombic perovskite structure at room temperature and an antiferromagnetic behaviour with a high Neel temperature $\left(\mathrm{T}_{\mathrm{N}}\right)[6-8]$. However, $\mathrm{LaFeO}_{3}$ compound is proficient to accommodate large variety of dopant ions, which may occupy $A$ or $B$ site and modify their physio-chemical properties. Further, physical nature of the dopants has greater influences on physical properties, and it can be tuned easily [9-11]. In addition, substitution or doped at different sites of $\mathrm{LaFeO}_{3}$ leads to decrease in their crystallite size and increases the surface area thus results in enhanced photocatalytic activity and magnetization $[12,13]$.

Recently, Ti substituted $\mathrm{LaFeO}_{3}$ by different synthesis method was reported by various research groups, the visible light photocatalytic properties of $\mathrm{LaFeO}_{3}$ by adding $\mathrm{TiO}_{2}$ synthesized by hydrothermal method demonstrated by dhinesh kumar et al [14]. The exchange bias effect in $\mathrm{Ti}$ doped $\mathrm{SrFeO}_{3}$ nanocrystalline compounds, reveals the ferromagnetic and antiferromagnetic interactions based on super exchange and ferromagnetic double exchange interactions [15]. The electrical properties and enhanced multi-functional properties of the oxide materials was achieved by adding dopants [5]. The magnetization of $\mathrm{LaFeO}_{3}$ compounds increased with decreasing particle size and the shift in Curie temperature $\left(T_{C}\right)$ was observed [4]. It has been reported that both the doping and synthesis technique might decrease the crystallite size thus results improved magnetization. 
To improve the electrical properties of $\mathrm{LaFeO}_{3}$ compounds different kinds of substitutions $\mathrm{La}_{0.5} \mathrm{Al}_{0.5} \mathrm{FeO}_{3}$ [16], $\mathrm{La}_{1-x} \mathrm{Zn}_{x} \mathrm{FeO}_{3}$ [17], $\mathrm{La}_{1 / 3} \mathrm{Sr}_{2 / 3} \mathrm{FeO}_{3-\mathrm{d}}$ [18], $\mathrm{LaZn}_{\mathrm{x}} \mathrm{Fe}_{1-\mathrm{x}} \mathrm{O}_{3}$ [19, 20], $\mathrm{La}_{1-x} \mathrm{Ca}_{\mathrm{x}} \mathrm{FeO}_{3-\mathrm{d}}$ [21], $\mathrm{La}_{0.8} \mathrm{Sr}_{0.2} \mathrm{Fe}_{1-\mathrm{x}} \mathrm{Cu}_{\mathrm{x}} \mathrm{O}_{3-\mathrm{d}}$ [22] on $\mathrm{A}$ and/or $\mathrm{B}$ site was done and investigated intensively. These materials shown stimulating and interesting properties such as extraordinary electrical conductivity, good thermal stability, high dielectric constant, piezoelectricity or ferroelectricity and low dielectric loss. Thus, the substitution of di-valent or tri-valent ions in lanthanum or iron sub-lattices has been precisely examined $[21,23,24]$. Accordingly, physical properties could be improved or modified specifically by the selection of appropriate doping at $\mathrm{La}^{3+}$ or $\mathrm{Fe}^{3+}$ site. In recently, a significant amount of dedication was remunerated to the perovskite-type $\mathrm{ABO}_{3}$ transition-metal oxides (TMOs) in photocatalytic field due to its trivial band gap (2.0-2.5 eV) and high chemical stability. In order to enhance the physical properties of the $\mathrm{LaFeO}_{3}$ compounds various ways have been used to synthesis such as co-precipitation technique [25], polymer pyrolysis method [5], hydrothermal method [26], polymerizable complex route [27], and microwave assisted method [28]. Identifying the suitable dopants and optimized synthesis procedure could make $\mathrm{LaFeO}_{3}$ is potential multifunctional material.

Hence, primary focus of the present work is to investigate the effect of substituting Ti on the structural, optical, dielectric and magnetic properties of $\mathrm{LaTi}_{x} \mathrm{Fe}_{1-\mathrm{x}} \mathrm{O}_{3}(\mathrm{x}=0,0.05,0.15,0.25)$ ceramic powders synthesized by conventional solid-state reaction method. One of the advantages of this method is lower manufacturing cost and simplicity. The conventional synthesized samples are characterized by powder X-ray diffractometer (XRD) with Rietveld refinement, Fourier transform infrared (FTIR) and Raman spectroscopy for evaluation of phase formation. The morphology, elemental composition and their distribution of the prepared samples were studied by scanning electron microscopy (SEM) with energy dispersive analysis (EDX). The UV-Vis and Photo luminescence (PL) spectroscopic techniques were analysed about the optical properties of synthesized samples. The electrical properties of the synthesized samples with respect to temperature were investigated. The magnetic properties of Ti-doped $\mathrm{LaFeO}_{3}$ samples were analysed using a Vibrated sample magnetometer (VSM) at room temperature. Interestingly, it was found that $\mathrm{Ti}$ substituted $\mathrm{LaFeO}_{3}$ considerably enhances the magnetization of $\mathrm{LaFeO}_{3}$ in $\mathrm{x}=0.05$ and $\mathrm{x}=0.25$.

\section{Experimental}

\subsection{Materials and synthesis}

Lanthanum (III) oxide $\left(\mathrm{La}_{2} \mathrm{O}_{3}\right)$, Iron oxide $\left(\mathrm{Fe}_{2} \mathrm{O}_{3}\right)$, Titanium oxide $\left(\mathrm{TiO}_{2}\right)$ precursors were used as a starting material (Sigma-Aldrich with $99.9 \%$ purity).

The title compounds $\mathrm{LaTi}_{x} \mathrm{Fe}_{1-\mathrm{x}} \mathrm{O}_{3},(\mathrm{x}=0,0.05,0.15,0.25)$ are prepared using conventional solid-state reaction method. The selected starting materials were weighed in the preferred stoichiometric proportion and well grounded ( $\sim$ hour) using agate mortar to produce a uniform fine powder. Then calcined at $900{ }^{\circ} \mathrm{C}$ for 12 hours, after the powders were well grounded, kept in an alumina crucible and sintered at 
$1000{ }^{\circ} \mathrm{C}$ for 6 hours with intermediate grinding. The prepared ferrite samples were permitted to cool down to room temperature at the rate of $5{ }^{\circ} \mathrm{C} /$ minute to attain homogeneity. Finally, the prepared ferrite powders were sintered at $1100^{\circ} \mathrm{C}$ for 6 hour and grounded well then subjected to various physical property measurements. The synthesized ferrite powders were pelletized using hydraulic press and used for dielectric measurements.

\subsection{Characterizations}

The structural formation and phase evaluation of the prepared powders were analyzed using Bruker D2 phaser X-ray diffractometer with $\mathrm{Cu} \mathrm{Ka}(1.5418 \AA)$ radiation. The XRD patterns were recorded in the $2 \theta$ range from 20 to $70^{\circ}$. Phase identifications were screened against the International Center for Diffraction Data (ICDD) PDF-4 database. The structural constraints, bond angle and bond length were obtained from the FULLPROF Rietveld refinement of the recorded XRD profiles. FTIR spectra were recorded from 500 to $1750 \mathrm{~cm}^{-1}$ using Bruker Alpha FTIR Spectrophotometer. Raman spectra were recorded at room temperature over the range of $100-1000 \mathrm{~cm}^{-1}$ using HR-800 UV Spectrophotometer in Horiba JobinYvon, with an excitation wavelength of $488 \mathrm{~nm}$ using He-Ne laser. The surface morphology, elemental mapping and quantitative analyses of the prepared samples were studied using JEOL ZEM Scanning Electron Microscopy (SEM) equipped with energy dispersive spectrometer (EDX). The UV-Vis absorption spectra were carried out using Perkin-Elmer spectrophotometer (200-800 nm). The PL emission spectra was recorded using 'Horiba Jobin-Yvon Fluoromax 4 spectro fluorometer. Magnetic measurements were done by Lakeshore (MODEL-7407) vibrating sample magnetometer (VSM) at room temperature. The frequency and temperature dependent dielectric measurements were carried out by Wayne Kerr-LCR 4275 in the frequency range of $10 \mathrm{~Hz}$ to $1 \mathrm{MHz}$.

\section{Results And Discussion}

\subsection{Powder X-ray Diffraction Analysis}

Figure 1a shows the XRD patterns of $\mathrm{Ti}$ substituted $\mathrm{LaFeO}_{3}$ ferrite powders. All synthesized samples reveal the peaks reliable to the standard orthorhombic structure of $\mathrm{LaFeO}_{3}$ (JCPDS No. 037-1493) with space group $P b n m$. From the diffraction pattern, the prepared powders are well crystalline in nature. In addition, all the peaks are shifted towards higher $(2 \theta)$ angle, whereas the highest $\mathrm{Ti}(\mathrm{x}=0.15)$ substitution shows the shift at higher $(2 \theta)$ angle with peak broadening, this may be ascribed to the lattice distortion and variation in their ionic radius as shown in Fig. 1b. From these observations, lattice constants decrease with increasing in amount of Ti substitution owing to smaller radius of the substituents compared with higher value of host lattice. The refined crystallographic parameters such as $R_{p}, R_{w p}, R_{\text {exp }}$, $\chi^{2}$ along with unit cell constraints are listed in Table 1 . The average crystallite size of the synthesized sample is evaluated using Scherrer's formula [29]: 


$$
D=\frac{K \lambda}{\beta \cos \theta}
$$

$k$ is a constant, $\lambda$ is a wavelength of $\mathrm{X}$-ray, $\theta$ is diffraction angle and $\beta$ is fullwidth at half maxima (FWHM). |

The crystallite size was calculating from high intensity peak (200) at $32.2^{0}$. The crystallite size was decreases with increases of Ti concentration except $(x=0.15)$ which may suggest that the $x=0.15$ is the right degree of substitution concentration for La-Fe-O lattice as mentioned in Table 1. It is seen that average bond distances of Fe-O are $2.00 \AA, 2.00 \AA, 1.88 \AA$ and $1.99 \AA$ for $(x=0$ to 0.25$)$ respectively. The minimum and maximum bond distances of O-La are $2.37 \AA$ and $3.27 \AA$ for pristine $\mathrm{LaFeO}_{3}$, then $2.42 \AA$ and $3.15 \AA$ is for $(x=0.05), 2.41 \AA$ and $3.08 \AA(x=0.15), 2.42 \AA$ and $3.08 \AA(x=0.25)$ correspondingly. The observed small inconsistencies among bond distances and lattice parameters at presence of $\mathrm{Ti}$ in $\mathrm{LaFeO}_{3}$ is due to strain, difference in ionic radius. Hence, the XRD analysis confirm the formation of $\mathrm{LaFeO}_{3}$ perovskite structure and substitution of Ti without altering the crystal structure.

\subsection{FTIR analysis}

The FTIR spectra of prepared Ti substituted $\mathrm{LaFeO}_{3}$ ferrite powders displayed in Fig. 2. The spectra illustrated the strong and broad vibrational band at $550-600 \mathrm{~cm}^{-1}$, which is ascribed to the antisymmetric stretching vibrations of $\mathrm{Fe}-\mathrm{O}$ and $\mathrm{O}-\mathrm{Fe}-\mathrm{O}$ of $\mathrm{FeO}_{6}$ octahedral and tetrahedral units of perovskite $\mathrm{ABO}_{3}$ [30]. Typically, IR bands from $300-1000 \mathrm{~cm}^{-1}$ are allocated to the vibration of inorganic ions in the crystal system. The existence of a band around $560 \mathrm{~cm}^{-1}$ strongly suggests the Me-O in tetrahedral sites [31], which emphasis that the La-Ti crystalline are essentially formed and the materials prepared at higher temperature indicate better crystalline nature.

\subsection{Raman spectroscopy analysis}

Figure 3 shows the Raman spectra of $\mathrm{LaTi}_{x} \mathrm{Fe}_{1-\mathrm{x}} \mathrm{O}_{3}(\mathrm{x}=0,0.05,0.15,0.25)$ synthesized compounds. Gradual changes observed in the raman spectra can be associated to the alteration of local structural disorders. Since, $\mathrm{LaFeO}_{3}$ belongs to orthorhombic structure with $\mathrm{Pbnm}$ space group. The predicted raman modes by group theory given as [32],

$\Gamma_{\text {opt,Pbnm }}=7 A_{g}(R)+7 B_{1 g}(R)+5 B_{2 g}(R)+5 B_{3 g}(R)+8 A_{u}(S)+7 B_{1 u}(I R)+9 B_{2 u}(I R)+9 B_{3 u}(I R)+B_{1 u}(a c)+$ $\mathrm{B}_{2 \mathrm{u}}(\mathrm{ac})+\mathrm{B}_{3 \mathrm{u}}(\mathrm{ac})(2)$

Out of these, only $A_{g}, B_{1 g}, B_{2 g}$ and $B_{3 g}$ are 24 Raman active modes and $B_{1 u}, B_{2 u}$ and $B_{3 u}$ are $25 I R$ active modes. Where R, IR, ac and S are Raman active, infrared active, acoustic and silent modes respectively. 
Among all, 60 normal modes and 24 are Raman active modes $\left(7 A_{g}+7 B_{1 g}+5 B_{2 g}+5 B_{3 g}\right)$ [32].

To extract more information from raman spectra lorentzian fit was used and the parameters are listed in Table 2. On deconvolution, the peak location of each component, that is the regular frequency $\left(\mathrm{cm}^{-1}\right)$ of each Raman active modes are shown in Fig. 4. With the $\mathrm{LaFeO}_{3}$ system have peaks around $146 \mathrm{~cm}^{-1}$, $171 \mathrm{~cm}^{-1}, 284 \mathrm{~cm}^{-1}, 425 \mathrm{~cm}^{-1}, 630 \mathrm{~cm}^{-1}$ and $785 \mathrm{~cm}^{-1}$ the appearance of an additional $\mathrm{A}_{\mathrm{g}}$ and $\mathrm{B}_{\mathrm{g}}$ modes. Similarly, $A_{g}$ and $B_{g}$ modes at $150 \mathrm{~cm}^{-1}, 436 \mathrm{~cm}^{-1}$ are completely available in all compounds. As shown in Fig. 4, the peak at $150 \mathrm{~cm}^{-1}$ shifted to $153 \mathrm{~cm}^{-1}$, the peaks $141 \mathrm{~cm}^{-1}, 165 \mathrm{~cm}^{-1}, 171 \mathrm{~cm}^{-1}$ are merged $150 \mathrm{~cm}^{-1}$ and the peak at $624 \mathrm{~cm}^{-1}$ shifted to $778 \mathrm{~cm}^{-1}$ as the substituting concentration was increased to 0.25 . As displayed Fig. 4, the increasing intensity of the peak at $624 \mathrm{~cm}^{-1}$ also reveals that the motions of $\mathrm{LaFeO}_{3}$ were affected by Ti substituting, the small variation in position of strong band and induced newer Raman active bands $687 \mathrm{~cm}^{-1}$ and $778 \mathrm{~cm}^{-1}$ confirm the incorporation of Ti in the $\mathrm{LaFeO}_{3}$ lattice.

\subsection{Morphology and compositional analysis}

Figure 5(a-d) demonstrate the SEM images of synthesized ferrite powders. Well recognized micro structural features and morphology was achieved. The SEM images exhibited that the microstructures comprised of submicron level particle. The pristine $\mathrm{LaFeO}_{3}$ sample seemed to be small agglomerated spherical particles. In all Ti substituted $\mathrm{LaFeO}_{3}$ compounds clearly exhibit the spherical-shaped particles and it can be understood from Fig. 5(a-d). The modification in morphological behaviour of prepared ferrites could be owing to consequence of substituting Ti concentration. Energy dispersive X-ray analysis (EDX) was assisted to examine the purity and chemical composition of prepared Ti substituted $\mathrm{LaFeO}_{3}$ ferrite powders, the shape of calcined synthesized samples is exposed in Fig. 5(a-d). In this investigation, lanthanum ( $\mathrm{La})$, iron $(\mathrm{Fe})$, oxygen $(\mathrm{O})$ and titanium $(\mathrm{Ti})$ were present in the prepared samples and elemental distributions were clearly shown in Fig. 6(a-d).

\subsection{Optical properties}

Figure 7 presents the UV-Visible spectra of prepared La-Ti ferrite powders in the wavelength range of 200-800 $\mathrm{nm}$, recorded at room temperature. The strong absorption edge at $590 \mathrm{~nm}$ is ascribed to the electronic transition from the valence state to the conduction state, $\mathrm{O}_{2 p} \rightarrow \mathrm{Fe}_{3 \mathrm{~d}}$. In Fig. 8 indicates the absorbance spectra allows to calculate the optical bandgap of the compound established on the absorption edge perceived at $590 \mathrm{~nm}$ and it was found to be $2.10 \mathrm{eV}$ using Tauc equation [33].

$a h v=A\left(h v-E_{g}\right)^{n}(3)$

$a$ is absorption coefficient, $E_{g}$ is the direct bandgap, hv is the photon energy and $A$ is a constant. The extrapolation of the linear parts of curve toward absorption equal to zero gives $\mathrm{E}_{\mathrm{g}}$ for direct transitions. The evaluated optical bandgaps are observed in the range of 1.85-2.02 eV. The results are in reliable with 
the earlier reported value of $2.10 \mathrm{eV}$. These small bandgap values of the prepared compounds are interesting for photocatalytic applications [25].

\subsection{Photoluminescence Studies}

Figure 9 shows the emission and excitation spectra for a prepared perovskite ferrite samples. Excitation spectra corresponding to $356 \mathrm{~nm}$ and it transition ${ }^{1} \mathrm{~S}_{0} \rightarrow{ }^{3} \mathrm{P}_{1}$ is shown in Fig. 9 (inset). Broad emission peak centered at $388 \mathrm{~nm}$ reveals the characteristic of $\mathrm{La}^{3+}-\mathrm{O}^{2-}$ charge transfer process, along with sharp peaks due to intra $\mathrm{f}$ transitions of $\mathrm{La}^{3+}$ ion, including ${ }^{3} \mathrm{P}_{2} \rightarrow{ }^{1} \mathrm{~S}_{0}$ (388 to $\left.441 \mathrm{~nm}\right),{ }^{3} \mathrm{P}_{1} \rightarrow{ }^{1} \mathrm{~S}_{0}$ (450 \& $476 \mathrm{~nm}$ ) respectively. The sharp peak at $388 \mathrm{~nm}$ is attributed to ${ }^{3} \mathrm{P}_{2} \rightarrow{ }^{1} \mathrm{~S}_{0}$ transition. The intensity of the peak $388 \mathrm{~nm}$ is stronger than the others, which are related to the emission wavelengths of near UV chips. The charge transfers band (CTB) excitation sharp peak reflects the electronic excitation of $\mathrm{O}^{2-} \rightarrow \mathrm{La}^{3+}$ and $\mathrm{O}^{2-} \rightarrow \mathrm{Fe}^{3+}$, whose intensity was the highest among all the excitation sharp peaks. Furthermore, the $f-f$ transitions show that energy is efficiently transferred to the La-Fe-O host lattice. The related wavelength of the excitation peaks of La ions $4 \mathrm{f} \mathrm{levels}$ is the same as that found in the literature [34-36]. The detailed $\mathrm{Ti}$ substituted $\mathrm{LaFeO}_{3}$ electronic transitions with the index are listed in Table 3. In relation to the energy level diagram of the optical transitions within $\mathrm{Ti}$, Fe ions schematically represented by Fig. 10, such emission bands correspond to the transitions of $\mathrm{La}$, Ti and Fe ions, which are mainly contributed by the intra band transition of $4 \mathrm{f}$ configurations in rare earth elements. Strong $\mathrm{La}^{3+}$ emission has been observed from the samples on exciting at the charge transfer peak maximum. Then the emission spectra results suggest that the potential candidates for making light emitting materials and photocatalytic applications [35].

\subsection{Dielectric Measurement}

Figure 13 and 14 shows the temperature dependence dielectric constant and tangent loss for all the prepared $\mathrm{LaTi}_{1-x} \mathrm{Fe}_{\mathrm{x}} \mathrm{O}_{3}(\mathrm{x}=0,0.05,0.15,0.25)$ ferrite compounds. The frequency range could be perceived that the dielectric constant is intensely dependence on the sintering temperature. For each sample, the dielectric constant increases rapidly at the frequency region between $10 \mathrm{~Hz}$ to $100 \mathrm{KHz}$ and the become constants at higher frequency region. From Figs. 12 and 14, the increasing of $\mathrm{Ti}$ concentration, the dielectric loss decreases which depends on the frequency as well as temperature. Generally, the four types of electrical polarization processes (electronic, ionic, dipolar, and interfacial polarization or space charge polarization) give the dielectric properties [38-40]. At lower frequency region, all types of polarization process can follow the modification of external field, giving enhancement to a high dielectric constant [41]. The frequency increases, space charge polarization process gradually intervals behind the change of external field, and dielectric constant going to be down. Further increasing the frequency, space charge polarization process cannot make any response to the external field, for this reason, the dielectric constant becomes constant at higher frequency region. In the pristine $\mathrm{LaFeO}_{3}$ compounds for the origin of giant dielectric properties revealed by Idrees et.al, [40]. The dielectric constant of the prepared materials can be expressed as following equation, 


$$
\epsilon^{\prime}=\frac{C_{\mathrm{p}} d}{\epsilon_{0} A}
$$

D-is the thickness of disc sample, $C_{p}$-is the capacitance, $\varepsilon_{0}$ is the permittivity, $A$ is the cross-sectional area of disc sample [42]. The frequency dependence of $\varepsilon^{\prime}$ and $\tan \delta$ of the prepared materials between $10^{2}$ and $10^{6} \mathrm{~Hz}$ measured in different temperatures and plotted in Figs. 11 and 12. These prepared ferrites demonstrated giant dielectric constant of (values) at $100 \mathrm{~Hz}$ matching with the grain size increases. Dielectric relaxation in these materials is ascribed to the electron hopping between $\mathrm{Fe}^{3+}$ and $\mathrm{Fe}^{4+}$, which is associated to that of pristine $\mathrm{LaFeO}_{3}$ ferrite as reported earlier [40]. This electron hopping mechanism is accountable for the polarization, foremost to the giant dielectric constant in $\mathrm{LaFeO}_{3}$ systems. Generally, high $\varepsilon^{\prime}$ values have been described by Khetre et.al and Mantas [41, 43]. High dielectric constant values in low frequencies it may be owing to the existence of space charge polarization [41].

\subsection{Magnetic property analysis}

The $\mathrm{M}-\mathrm{H}$ loop of the prepared $\mathrm{LaTi}_{x} \mathrm{Fe}_{1-x} \mathrm{O}_{3}(\mathrm{x}=0,0.05,0.15,0.25)$ ferrite powders are shown in Fig. 15. The substitution of non-magnetic Ti ions has a different site occupancy which decreases of the exchange interaction between $\mathrm{B}$ sites. Hence, by increasing the Ti concentration, it is possible to vary the magnetic properties of the prepared ferrite materials. Usually, $\mathrm{LaFeO}_{3}$ have been confirmed a canted antiferromagnetic (AFM) nature with a Neel temperature at $740 \mathrm{~K}$. Commonly, $\mathrm{La}^{3+}$ is nonmagnetic but subsequently all the electrons were paired. The main source of the magnetic properties is presented by magnetic moments of Fe. Hence, the ferromagnetic behavior of pure $\mathrm{LaFeO}_{3}$ is due to the spin canted magnetic moments of $\mathrm{Fe}$, which are arises from disordered surface spins [44]. Further, this performance is owing to the uncompensated spin which makes ferromagnetic shell surrounding the antiferromagnetic core, consequential in a net magnetization. For the prepared samples, $\mathrm{Ti}^{4+}$ ions have $3 \mathrm{~d}^{0}$ valence electrons that cannot contribute to ferromagnetic ordering. At higher contents of $\mathrm{Ti}$, there could be decrease in the particle size and coercivity $(\mathrm{Hc})$, which may increase the number of uncompensated spins, thus results in an improved magnetization. Some researchers have described the transposed relation of coercivity, and crystallite size based on domain theory [45]. In the present investigation, similar results were observed. Stoner-Wolfforth model clearly demonstrated that role of single domains and multidomains on their coercivity value as the particle size decreases, their Hc values also decreases [4548]. From Table 4, the coercivity is higher for pristine $\mathrm{LaFeO}_{3}$ compound. As Ti substituted in La-Fe-O lattice, the coercivity values decreases. Conversely at $x=0.15$, coercivity value increases, this may be due to the effect of Ti on crystallite size and shape, further increase in Ti concentration, there is a decrease in their values. All the prepared samples exhibit weak ferromagnetic behavior and pure sample shows high magnetization associated with 0.05 to $0.25 \mathrm{Ti}$ concentration. The magnetic parameters $\mathrm{Ms}, \mathrm{Mr}$, squareness ratio, $\mathrm{Hc}$ and anisotropy constant values are listed in Table 4. The existence of secondary phases and high concentrations of nonmagnetic ions $\left(\mathrm{Ti}^{4+}\right)$ can hide the domain wall motion [25]. The 
coercivity $(\mathrm{Hc})$, saturation magnetization $(\mathrm{Ms})$ values are decreases and increasing the nonmagnetic cations.

The observed change in magnetic properties, may be due to a high antiferromagnetic spin alignment of $\mathrm{Fe}^{3+}-\mathrm{O}^{2-}-\mathrm{Fe}^{3+}$ and $\mathrm{Fe}^{4+}-\mathrm{O}^{2-}-\mathrm{Fe}^{4+}$ super exchange interaction [25]. The substitution of $\mathrm{Ti}^{4+}$ ions may create a greater number of $\mathrm{Fe}^{3+}$ ions to ensure the charge impartiality which may enhance the double exchange (DE) interactions that results in higher magnetization $(x=0.25)$ [26]. The magnetization value is maximum at substitution of $\mathrm{Ti}(\mathrm{x}=0.25)$. Hence, the prepared materials may find useful for magnetic memory storage device applications.

\section{Conclusion}

The influences of $\mathrm{Ti}$ ion on structural, optical, magnetic and dielectric properties of $\mathrm{LaFeO}_{3}$ with different concentrations was investigated. The $\mathrm{LaFeO}_{3}$ ferrite powders were prepared by conventional solid-state reaction method. The refined structural parameters were revealing the structural information. The Me-O vibrations and local structural disorder were examined by Fourier transform infrared and Raman spectroscopy. SEM analysis was exhibits poly crystalline nature of prepared compounds. The optical and $\mathrm{PL}$ spectra clearly shows the effect of $\mathrm{Ti}$ on host lattice. The magnetic measurements were demonstrated the weak ferromagnetic behaviour of the prepared samples. We found that the coercivity is found to be maximum for pristine $\mathrm{LaFeO}_{3}$. Then it, accordingly, decreases on substituting Ti content, except for $\mathrm{x}=$ 0.15 . this probably understood in terms of variation in their crystallite size. Hence, from the above results, we have concluded that the prepared compounds are may useful for spintronics, magnetic memory devices applications.

\section{References}

1. Teresita VM, Manikandan A, Josephine BA, Sujatha S, Antony SA (2016) Electromagnetic Properties and Humidity-Sensing Studies of Magnetically Recoverable $\mathrm{LaMg}_{x} \mathrm{Fe}_{1-x} \mathrm{O}_{3-\delta}$ Perovskites Nanophotocatalysts by Sol-Gel Route. J Supercond Nov Magn 29:1691-1701. https://doi.org/10.1007/s10948-016-3465-7

2. Faye J, Baylet A, Trentesaux M, Royer S, Dumeignil F, Duprez D, Valange S, Tatibouët JM (2012) Influence of lanthanum stoichiometry in $\mathrm{La}_{1-x} \mathrm{FeO}_{3-\delta}$ perovskites on their structure and catalytic performance in $\mathrm{CH}_{4}$ total oxidation. Appl Catal B Environ 126:134-143. https://doi.org/10.1016/j.apcatb.2012.07.001

3. Cristóbal AA, Botta PM, Bercoff PG, Porto JM, López, Mechanosynthesis and magnetic properties of nanocrystalline $\mathrm{LaFeO}_{3}$ using different iron oxides, Mater ResBull44 (2009) 1036-1040. https://doi.org/10.1016/j.materresbull.2008.11.015

4. Lakshminarayanan N, Kuhn JN, Rykov SA, Millet JMM, Ozkan US, Doped $\mathrm{LaFeO}_{3}$ as SOFC catalysts: Control of oxygen mobility and oxidation activity, Catal Today, 2010: 446-450. 
https://doi.org/10.1016/j.cattod.2010.03.037

5. Phokha S, Hunpratup S, Pinitsoontorn S, Putasaeng B, Rujirawat S, Maensiri S (2015) Structure, magnetic, and dielectric properties of Ti-doped $\mathrm{LaFeO}_{3}$ ceramics synthesized by polymer pyrolysis method. Mater Res Bull 67:118-125. https://doi.org/10.1016/j.materresbull.2015.03.008

6. Saad AA, Khan W, Dhiman P, Naqvi AH, Singh M (2013) Structural, optical and magnetic properties of perovskite $\left(\mathrm{La}_{1}-\mathrm{Sr}_{\mathrm{x}}\right)\left(\mathrm{Fe}_{1}{ }_{\mathrm{x}} \mathrm{Ni}_{\mathrm{x}}\right) \mathrm{O}_{3}(\mathrm{x}=0.0,0.1$ \& 0. 2) nanoparticles. Electron Mater Lett 9:77-81. https://doi.org/10.1007/s13391-012-2103-1

7. $10.1155 / 2012 / 380306$

Thuy NT, Le Minh D, Size effect on the structural and magnetic properties of nanosized perovskite $\mathrm{LaFeO}_{3}$ prepared by different methods, Adv. Mater. Sci. Eng (2012 (2012)) https://doi.org/10.1155/2012/380306

8. Lee WY, Yun HJ, Yoon JW (2014) Characterization and magnetic properties of $\mathrm{LaFeO}_{3}$ nanofibers synthesized by electrospinning. J Alloys Compd 583:320-324. https://doi.org/10.1016/j.jallcom.2013.08.191

9. Manthiram A, Kim JH, Kim YN, Lee KT (2011) Crystal chemistry and properties of mixed ionicelectronic conductors. J Electroceramics 27:93-107. https://doi.org/10.1007/s10832-011-9635-x

10. Andoulsi R, Horchani-Naifer K, Férid M (2012) Structural and electrical properties of calcium substituted lanthanum ferrite powders. Powder Technol 230:183-187. https://doi.org/10.1016/j.powtec.2012.07.026

11. Properties and Applications of Perovskite-Type Oxides - Google Books Properties and Applications of Perovskite-Type Oxides - Google Books, https://books.google.co.in/books (1993) CRC Press, Madrid

12. Tang Li F, Liu Y, hong Liu R, min Sun Z, Zhao D (2010) C. guang Kou, Preparation of Ca-doped $\mathrm{LaFeO} 3$ nanopowders in a reverse microemulsion and their visible light photocatalytic activity. Mater Lett 64:223-225. https://doi.org/10.1016/j.matlet.2009.10.048

13. Hu W, Chen Y, Yuan H, Zhang G, Li G, Pang G, Feng S (2010) Hydrothermal synthesis, characterization and composition-dependent magnetic properties of $\mathrm{LaFe}_{1-}{ }_{\mathrm{x}} \mathrm{Cr}_{\mathrm{x}} \mathrm{O}_{3}$ system $(0 \leq \mathrm{x} \leq$ 1). J Solid State Chem 183:1582-1587. https://doi.org/10.1016/j.jssc.2010.04.041

14. Dhinesh Kumar R, Thangappan R, Jayavel $R$ (2017) Synthesis and characterization of $\mathrm{LaFeO}_{3} / \mathrm{TiO}_{2}$ nanocomposites for visible light photocatalytic activity. J Phys Chem Solids 101:25-33. https://doi.org/10.1016/j.jpcs.2016.10.005

15. Sendil Kumar A, Srinath S, Exchange bias effect in Ti doped nanocrystalline $\mathrm{SrFeO}_{3-\delta}$, AIP Adv. 4 (2014). https://doi.org/10.1063/1.4894486

16. Acharya S, Chakrabarti PK (2010) Some interesting observations on the magnetic and electric properties of $\mathrm{Al}^{3+}$ doped lanthanum orthoferrite $\left(\mathrm{La}_{0.5} \mathrm{Al}_{0.5} \mathrm{FeO}_{3}\right)$. Solid State Commun 150:12341237. https://doi.org/10.1016/j.ssc.2010.04.006 
17. Mukhopadhyay K, Mahapatra AS, Chakrabarti PK (2013) Multiferroic behavior, enhanced magnetization and exchange bias effect of $\mathrm{Zn}$ substituted nanocrystalline $\mathrm{LaFeO}_{3}\left(\mathrm{La}_{(1-\mathrm{x})} \mathrm{Zn}_{\mathrm{x}} \mathrm{FeO}_{3}, \mathrm{x}\right.$ $=0.10$, and 0.30). J Magn Magn Mater 329:133-141. https://doi.org/10.1016/j.jmmm.2012.09.063

18. Ying XN (2013) Charge order suppression in oxygen nonstoichiometric $\mathrm{La}_{1 / 3} \mathrm{Sr}_{2 / 3} \mathrm{FeO}_{3-\delta}$. Solid State Commun 169:20-23. https://doi.org/10.1016/j.ssc.2013.06.021

19. Hosseini SA, Sadeghi MT, Alemi A, Niaei A, Salari D, Kafi-Ahmadi L (2010) Synthesis, characterization, and performance of $\mathrm{LaZn}_{\mathrm{x}} \mathrm{Fe}_{1-\mathrm{x}} \mathrm{O}_{3}$ perovskite nanocatalysts for toluene combustion. Cuihua Xuebao/Chinese J Catal 31:747-750. https://doi.org/10.1016/S18722067(09)60083-8

20. Bhat I, Husain S, Khan W, Patil SI (2013) Effect of Zn doping on structural, magnetic and dielectric properties of $\mathrm{LaFeO}_{3}$ synthesized through sol-gel auto-combustion process. Mater Res Bull 48:45064512. https://doi.org/10.1016/j.materresbull.2013.07.028

21. Andoulsi R, Horchani-Naifer K, Férid M (2013) Electrical conductivity of $\mathrm{La}_{1}-\mathrm{Ca}_{x} \mathrm{FeO}_{3-\delta}$ solid solutions. Ceram Int 39:6527-6531. https://doi.org/10.1016/j.ceramint.2013.01.085

22. Natali Sora I, Caronna T, Fontana F, De Julián Fernández C, Caneschi A, Green M (2012) Crystal structures and magnetic properties of strontium and copper doped lanthanum ferrites. J Solid State Chem 191:33-39. https://doi.org/10.1016/j.jssc.2012.02.020

23. Bellakki MB, Kelly BJ, Manivannan V (2010) Synthesis, characterization, and property studies of (La, Ag) $\mathrm{FeO}_{3}(0.0 \leq x \leq 0.3)$ perovskites. $J$ Alloys Compd 489:64-71. https://doi.org/10.1016/j.jallcom.2009.08.059

24. Karpinsky DV, Troyanchuk IO, Sikolenko V, Efımov V, Kholkin AL, Electromechanical and magnetic properties of $\mathrm{BiFeO}_{3}-\mathrm{LaFeO}_{3}-\mathrm{CaTiO}_{3}$ ceramics near the rhombohedral-orthorhombic phase boundary, J Appl Phys 113 (2013). https://doi.org/10.1063/1.4801960

25. Sasikala C, Durairaj N, Baskaran I, Sathyaseelan B, Henini M, Manikandan E (2017) Transition metal titanium ( $\mathrm{Ti}$ ) doped $\mathrm{LaFeO}_{3}$ nanoparticles for enhanced optical structural and magnetic properties. $\mathrm{J}$ Alloys Compd 712:870-877. https://doi.org/10.1016/j.jallcom.2017.04.133

26. Sasikala C, Suresh G, Durairaj N, Baskaran I, Sathyaseelan B, Manikandan E, Srinivasan R, Moodley MK (2019) Chemical, Morphological, Structural, Optical, and Magnetic Properties of Transition Metal Titanium (Ti)-Doped $\mathrm{LaFeO}_{3}$ Nanoparticles. J Supercond Nov Magn 32:1791-1797. https://doi.org/10.1007/s10948-018-4879-1

27. Andoulsi R, Horchani-Naifer K, Férid M (2012) Structural and electrical properties of calcium substituted lanthanum ferrite powders. Powder Technol 230:183-187. https://doi.org/10.1016/j.powtec.2012.07.026

28. Farhadi S, Sepahvand S (2010) Microwave-assisted solid-state decomposition of $\mathrm{La}\left[\mathrm{Co}(\mathrm{CN})_{6}\right] \cdot 5 \mathrm{H}_{2} \mathrm{O}$ precursor: A simple and fast route for the synthesis of single-phase perovskite-type $\mathrm{LaCoO}_{3}$ nanoparticles. J Alloys Compd 489:586-591. https://doi.org/10.1016/j.jallcom.2009.09.117 
29. RameshKumar R, Ramachandran T, Natarajan K, Muralidharan M, Hamed F, Kurapati V (2019) Fraction of Rare-Earth (Sm/Nd)-Lanthanum Ferrite-Based Perovskite Ferroelectric and Magnetic Nanopowders. J Electron Mater 48:1694-1703. https://doi.org/10.1007/s11664-018-06897-7

30. Jeevanandam P, Koltypin Y, Palchik O, Gedanken A (2001) Synthesis of morphologically controlled lanthanum carbonate particles using ultrasound irradiation. J Mater Chem 11:869-873. https://doi.org/10.1039/b007370i

31. G.V.S.R. and Rao CN, Infrared and Electronic Spectra of Rare Earth Perovskites. Ortho- Chromites, Manganites and Ferrites, 1970. https://doi.org/10.1366/000370270774371426

32. Popa M, Frantti J, Kakihana M, Lanthanum ferrite $\mathrm{LaFeO}_{3+\mathrm{d}}$ nanopowders obtained by the polymerizable complex method, Solid State Ionics 154-155 (2002) 437-445. https://doi.org/10.1016/S0167-2738(02)00480-0

33. Tauc J, Grigorovici R, Vancu A (1966) Optical Properties and Electronic Structure of Amorphous Germanium. Phys Status Solidi 15:627-637. https://doi.org/10.1002/pssb.19660150224

34. Jaffar BM, Swart HC, Seed Ahmed HAA, Yousif A, Kroon RE (2019) Luminescence properties of Bi doped $\mathrm{La}_{2} \mathrm{O}_{3}$ powder phosphor. J Lumin 209:217-224. https://doi.org/10.1016/j.jlumin.2019.01.044

35. Jbeli R, Boukhachem A, Saadallah F, Alleg S, Amlouk M, Ezzaouïa H, Synthesis and physical properties of Fe doped $\mathrm{La}_{2} \mathrm{O}_{3}$ thin films grown by spray pyrolysis for photocatalytic applications, Mater Res Express 6 (2019). https://doi.org/10.1088/2053-1591/ab0e29

36. Jbeli R, Boukhachem A, Ben Jemaa I, Mahdhi N, Saadallah F, Elhouichet H, Alleg S, Amlouk M, Ezzaouiia $\mathrm{H}$ (2017) An enhancement of photoluminescence property of $\mathrm{Ag}$ doped $\mathrm{La}_{2} \mathrm{O}_{3}$ thin films at room temperature, Spectrochim. Acta - Part A Mol. Biomol Spectrosc 184:71-81. https://doi.org/10.1016/j.saa.2017.04.072

37. Sales BC, Skutterudites F (2003) Handb Phys Chem Rare Earths 33:1-34. https://doi.org/10.1016/S0168-1273(02)33001-0

38. Lee SJ, Kang KY, Han SK (1999) Low-frequency dielectric relaxation of $\mathrm{BaTiO}_{3}$ thin-film capacitors. Appl Phys Lett 75:1784-1786. https://doi.org/10.1063/1.124819

39. Wang CH, Liu ZF, Yu L, Tian ZM, Yuan SL (2011) Structural, magnetic and dielectric properties of $\mathrm{Bi}_{5}$ ${ }_{-x} \mathrm{La}_{\mathrm{x}} \mathrm{Ti}_{3} \mathrm{Co}_{0.5} \mathrm{Fe}_{0.5} \mathrm{O}_{15}$ ceramics. Mater Sci Eng B Solid-State Mater Adv Technol 176:1243-1246. https://doi.org/10.1016/j.mseb.2011.06.016

40. Idrees M, Nadeem M, Atif M, Siddique M, Mehmood M, Hassan MM (2011) Origin of colossal dielectric response in $\mathrm{LaFeO}_{3}$. Acta Mater 59:1338-1345. https://doi.org/10.1016/j.actamat.2010.10.066

41. Khetre SM, Jadhav HV, Jagadale PN, Kulal SR, Bamane SR, Studies on electrical and dielectric properties of $\mathrm{LaFeO}_{3}, 2011$. (accessed January 30, 2020)

42. Madhan K, Thiyagarajan R, Jagadeeshwaran C, Paul Blessington Selvadurai A, Pazhanivelu V,

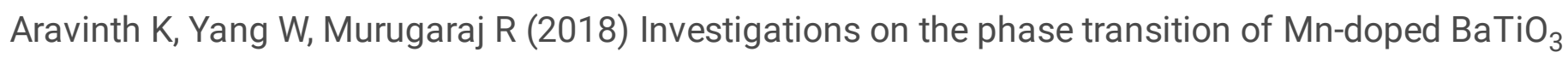


multifunctional ferroelectric ceramics through Raman, dielectric, and magnetic studies. J Sol-Gel Sci Technol 88:584-592. https://doi.org/10.1007/s10971-018-4835-3

43. Mantas PQ (1999) Dielectric response of materials: Extension to the Debye model. J Eur Ceram Soc 19:2079-2086. https://doi.org/10.1016/s0955-2219(98)00273-8

44. Phokha S, Pinitsoontorn S, Rujirawat S, Maensiri S (2015) Polymerized complex synthesis and effect of $\mathrm{Ti}$ dopant on magnetic properties of $\mathrm{LaFeO}_{3}$ nanoparticles. J Nanosci Nanotechnol 15:91719177. https://doi.org/10.1166/jnn.2015.11407

45. Stoner EC, Wohlfarth EP (1948) A Mechanism of Magnetic Hysteresis in Heterogeneous Alloys. Philos Trans R Soc A Math Phys Eng Sci 240:599-642. https://doi.org/10.1098/rsta.1948.0007

46. Padmapriya G, Manikandan A, Krishnasamy V, Jaganathan SK, Antony SA (2016) Spinel $\mathrm{Ni}_{x} \mathrm{Zn}_{1-}$ ${ }_{x} \mathrm{Fe}_{2} \mathrm{O}_{4}(0.0 \leq \mathrm{x} \leq 1.0)$ nano-photocatalysts: Synthesis, characterization and photocatalytic degradation of methylene blue dye. J Mol Struct 1119:39-47.

https://doi.org/10.1016/j.molstruc.2016.04.049

47. Shah AH, Manikandan E, Basheer Ahamed M, Ahmad Mir D, Ahmad Mir S (2014) Antibacterial and Blue shift investigations in sol-gel synthesized $\mathrm{Cr}_{x} \mathrm{Zn}_{1-\mathrm{x}} \mathrm{O}$ Nanostructures. J Lumin 145:944-950. https://doi.org/10.1016/j.jlumin.2013.09.023

48. Barathiraja C, Manikandan A, Uduman Mohideen AM, Jayasree S, Antony SA (2016) Magnetically Recyclable Spinel $\mathrm{Mn}_{x} \mathrm{Ni}_{1-x} \mathrm{Fe}_{2} \mathrm{O}_{4}(x=0.0-0.5)$ Nano-photocatalysts: Structural, Morphological and Opto-magnetic Properties. J Supercond Nov Magn 29:477-486. https://doi.org/10.1007/s10948015-3312-2

\section{Tables}


Table 1

Structural constraints, bond angle and bond length of $\mathrm{LaTi}_{x} \mathrm{Fe}_{1-\mathrm{x}} \mathrm{O}_{3}(\mathrm{x}=0,0.05$, $0.15,0.25)$ as tabulated from the Rietveld analysis.

\begin{tabular}{|lllll|}
\hline Structural parameters & $\mathbf{x}=\mathbf{0}$ & $\mathbf{x}=\mathbf{0 . 0 5}$ & $\mathbf{x}=\mathbf{0 . 1 5}$ & $\mathrm{x}=\mathbf{0 . 2 5}$ \\
\hline $\mathbf{a}(\AA)$ & 5.5595 & 5.5520 & 5.5477 & 5.5438 \\
\hline $\mathbf{b}(\AA)$ & 5.5694 & 5.5630 & 5.5543 & 5.5552 \\
\hline $\mathbf{c}(\AA)$ & 7.8603 & 7.8430 & 7.8556 & 7.8505 \\
\hline Volume & 243.70 & 243.39 & 242.06 & 241.77 \\
\hline $\mathbf{W}_{\mathrm{Rp}}(\%)$ & 14.4 & 15.6 & 14.8 & 14.8 \\
\hline Wp $(\%)$ & 9.88 & 10.6 & 11.1 & 10.2 \\
\hline $\mathbf{X}^{2}$ & 1.91 & 3.32 & 6.11 & 3.39 \\
\hline $\mathbf{R}_{\text {exp }}$ & 7.15 & 5.80 & 4.50 & 5.56 \\
\hline $\mathbf{a}$ & 90 & 90 & 90 & 90 \\
\hline $\boldsymbol{\beta}$ & 90 & 90 & 90 & 90 \\
\hline $\mathbf{Y}$ & 90 & 90 & 90 & 90 \\
\hline Crystallite size (nm) & 98 & 79 & 59 & 72 \\
\hline Fe- O bond length $(\AA)$ & 2.00 & 2.00 & 1.88 & 1.99 \\
\hline Minimum Fe - O bond length $(\AA)$ & 2.37 & 2.42 & 2.41 & 2.42 \\
\hline Maximum Fe - O bond length $(\AA)$ & 3.27 & 3.15 & 3.08 & 3.08 \\
\hline
\end{tabular}


Table 2

Symmetry assignments of $\mathrm{LaTi}_{x} \mathrm{Fe}_{1-x} \mathrm{O}_{3}(\mathrm{x}=0,0.05,0.15,0.25)$ ceramic compounds.

\begin{tabular}{|c|c|c|c|}
\hline & \multicolumn{3}{|c|}{ Details of the compounds and Symmetry assignments } \\
\hline $\mathrm{LaFeO}_{3}$ & \multicolumn{3}{|c|}{ LaTi $_{0.05} \mathrm{Fe}_{0.95} \mathrm{O}_{3} \mathrm{LaTi}_{0.15} \mathrm{Fe}_{0.85} \mathrm{O}_{3} \mathrm{LaTi}_{0.25} \mathrm{Fe}_{0.75} \mathrm{O}_{3}$} \\
\hline \multirow[t]{3}{*}{$146\left(A_{g}\right)$} & & & $141\left(A_{g}\right)$ \\
\hline & $150\left(A_{g}\right)$ & $153\left(A_{g}\right)$ & $153\left(A_{g}\right)$ \\
\hline & & & $165\left(B_{g}\right)$ \\
\hline $171\left(A_{g}\right)$ & & & $171\left(B_{g}\right)$ \\
\hline $284\left(A_{g}\right)$ & $293\left(A_{g}\right)$ & $284\left(A_{g}\right)$ & $274\left(B_{g}\right)$ \\
\hline \multirow[t]{2}{*}{$425\left(B_{g}\right)$} & $432\left(B_{g}\right)$ & $449\left(B_{g}\right)$ & $436\left(B_{g}\right)$ \\
\hline & & & $501\left(A_{g}\right)$ \\
\hline $630\left(A_{g}\right)$ & $624\left(A_{g}\right)$ & $673\left(A_{g}\right)$ & $687\left(A_{g}\right)$ \\
\hline $785\left(B_{g}\right)$ & $791\left(B_{g}\right)$ & $771\left(B_{g}\right)$ & $778\left(B_{g}\right)$ \\
\hline
\end{tabular}

Table 3

Details of emission spectra of $\mathrm{LaTi}_{x} \mathrm{Fe}_{1-x} \mathrm{O}_{3}(x=0,0.05,0.15,0.25)$ ceramic compounds.

\begin{tabular}{|llll|}
\hline Wavelength $(\mathrm{nm})$ & Energy $(\mathrm{eV})$ & Wavenumber $\left(\mathrm{cm}^{-1}\right)$ & Transition \\
\hline 388 & 3.19 & 25773 & ${ }^{3} \mathrm{P}_{2} \rightarrow{ }^{1} \mathrm{~S}_{0}$ \\
\hline 408 & 3.03 & 24509 & ${ }^{3} \mathrm{P}_{2} \rightarrow{ }^{1} \mathrm{~S}_{0}$ \\
\hline 415 & 2.98 & 24096 & ${ }^{3} \mathrm{P}_{2} \rightarrow{ }^{1} \mathrm{~S}_{0}$ \\
\hline 428 & 2.89 & 23364 & ${ }^{3} \mathrm{P}_{2} \rightarrow{ }^{1} \mathrm{~S}_{0}$ \\
\hline 433 & 2.86 & 23094 & ${ }^{3} \mathrm{P}_{2} \rightarrow{ }^{1} \mathrm{~S}_{0}$ \\
\hline 441 & 2.81 & 22675 & ${ }^{3} \mathrm{P}_{2} \rightarrow{ }^{1} \mathrm{~S}_{0}$ \\
\hline 450 & 2.75 & 22222 & ${ }^{3} \mathrm{P}_{1} \rightarrow{ }^{1} \mathrm{~S}_{0}$ \\
\hline 476 & 2.60 & 21008 & ${ }^{3} \mathrm{P}_{1} \rightarrow{ }^{1} \mathrm{~S}_{0}$ \\
\hline
\end{tabular}


Table 4

Magnetic parameters of $\mathrm{LaTi}_{x} \mathrm{Fe}_{1-\mathrm{x}} \mathrm{O}_{3}(\mathrm{x}=0,0.05,0.15,0.25)$ ceramic compounds

\begin{tabular}{|llllll|}
\hline Sample & $\mathrm{Ms}(\mathrm{emu} / \mathrm{g})$ & $\mathrm{Mr}(\mathrm{emu} / \mathrm{g})$ & $\mathrm{Mr} / \mathrm{Ms}$ & $\mathrm{Hc}(\mathrm{Oe})$ & Anisotropy constant (K) \\
\hline $\mathrm{LaFeO}_{3}$ & 0.108 & 0.01 & 0.093 & 1409 & 158.52 \\
\hline $\mathrm{LaTi}_{0.05} \mathrm{Fe}_{0.95} \mathrm{O}_{3}$ & 2.971 & 0.232 & 0.078 & 749 & 2074.02 \\
\hline $\mathrm{LaTi}_{0.15} \mathrm{Fe}_{0.85} \mathrm{O}_{3}$ & 0.129 & 0.0212 & 0.165 & 1231 & 49.148 \\
\hline $\mathrm{LaTi}_{0.25} \mathrm{Fe}_{0.75} \mathrm{O}_{3}$ & 3.101 & 0.332 & 0.107 & 805 & 12.230 \\
\hline
\end{tabular}

Figures
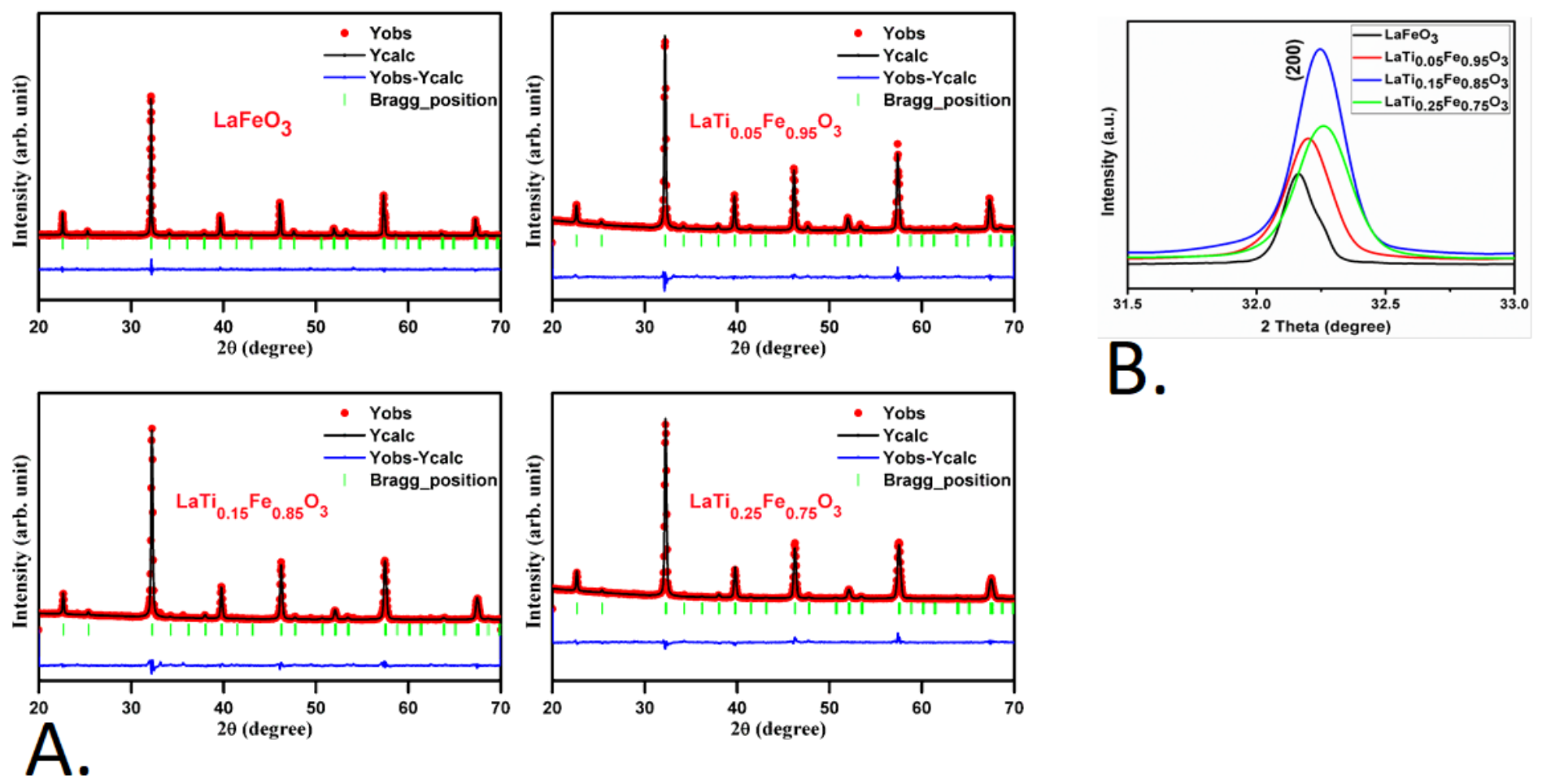

Figure 1

A. Rietveld refinement patterns of synthesized LaTixFe1- $x O 3(x=0,0.05,0.15,0.25)$ ceramic samples. $B$. XRD patterns enlarged view of (200) high intensity peak of synthesized LaTixFe1-xO3 $(x=0,0.05,0.15$, 0.25 ) ceramic compounds 


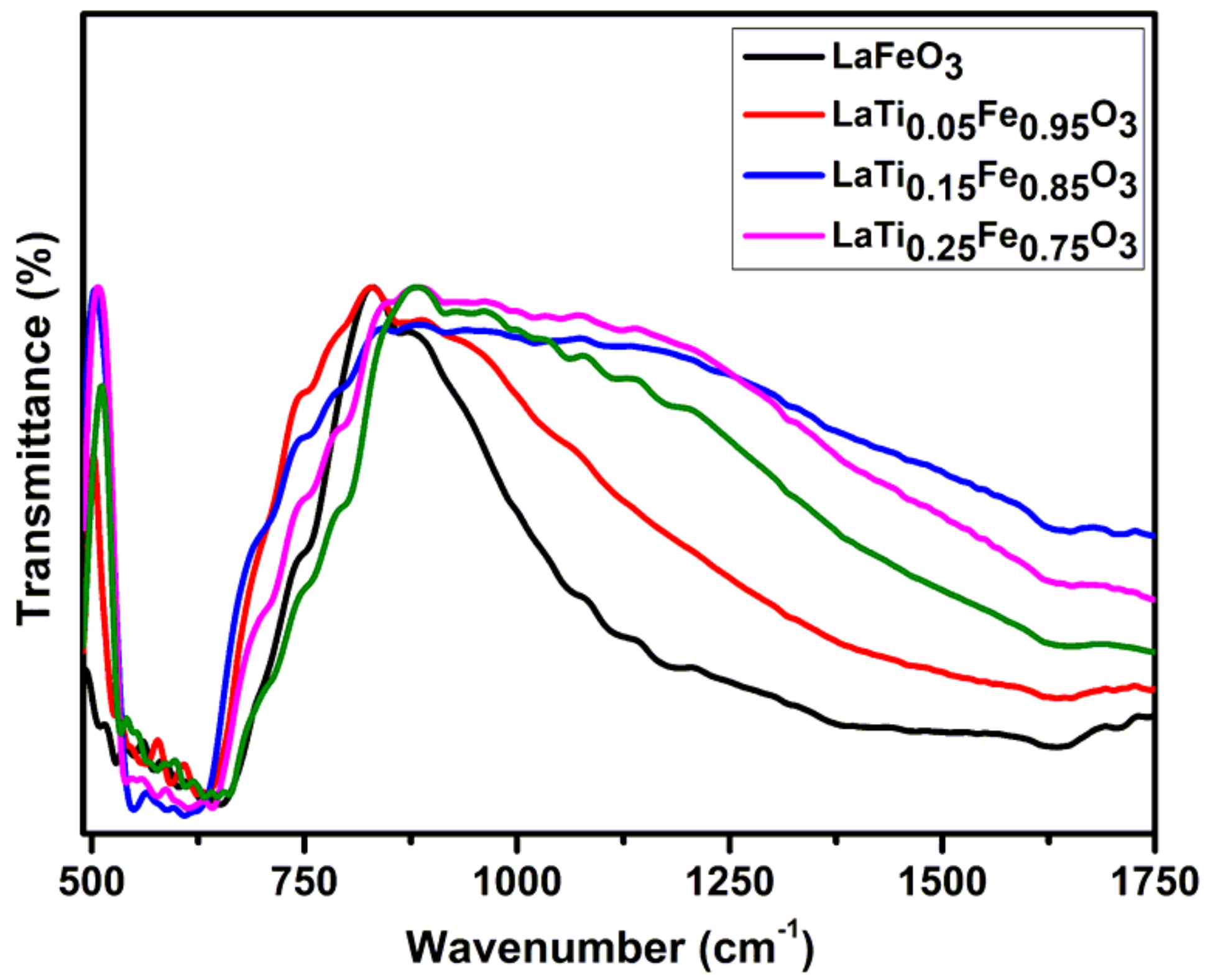

Figure 2

FTIR spectrum of synthesized LaTixFe1-x03 $(x=0,0.05,0.15,0.25)$ ceramic samples. 


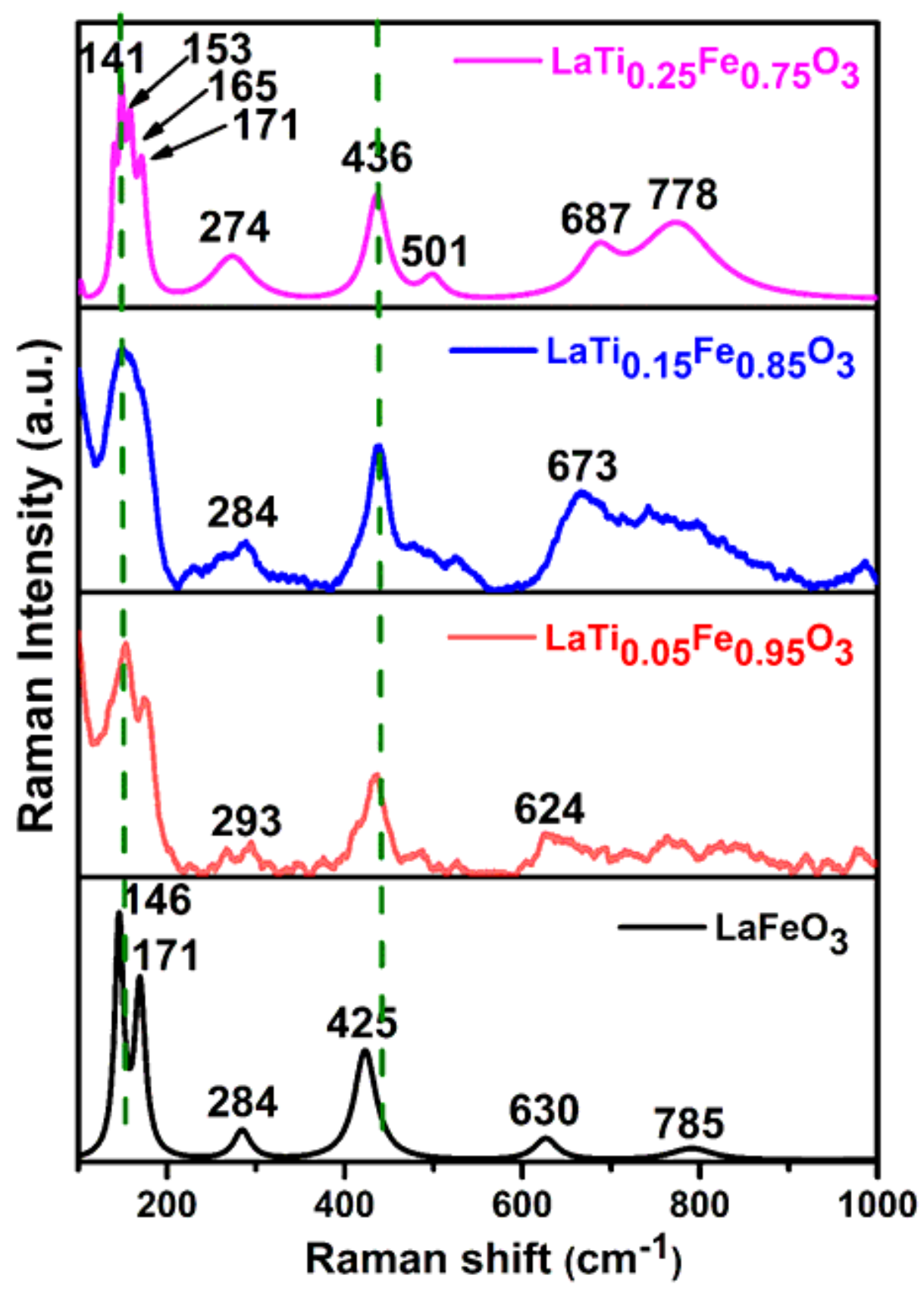

Figure 3

Raman spectra obtained from LaTixFe1-xO3 $(x=0,0.05,0.15,0.25)$ ceramic compounds. 

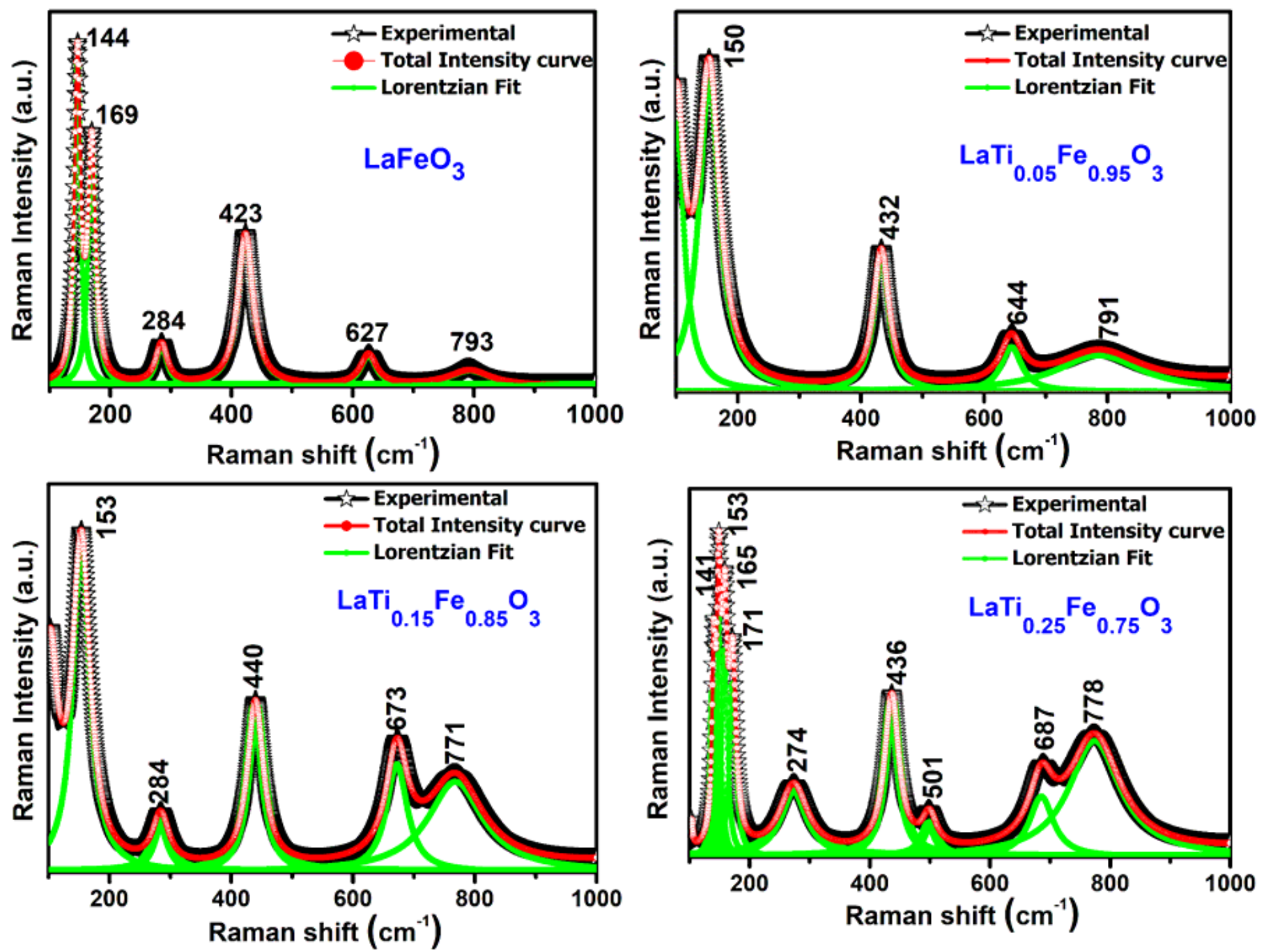

Figure 4

Fitting curves of the Raman signal for the LaTixFe1-xO3 $(x=0,0.05,0.15,0.25)$ ceramic compounds with Lorentzian line shapes. The Black lines with shapes are experimental data, the strong curves with green shade with shapes are the fitting of Lorentzian shapes and the solid curves with red shade with shapes are the total intensities of the Lorentzian lines. 

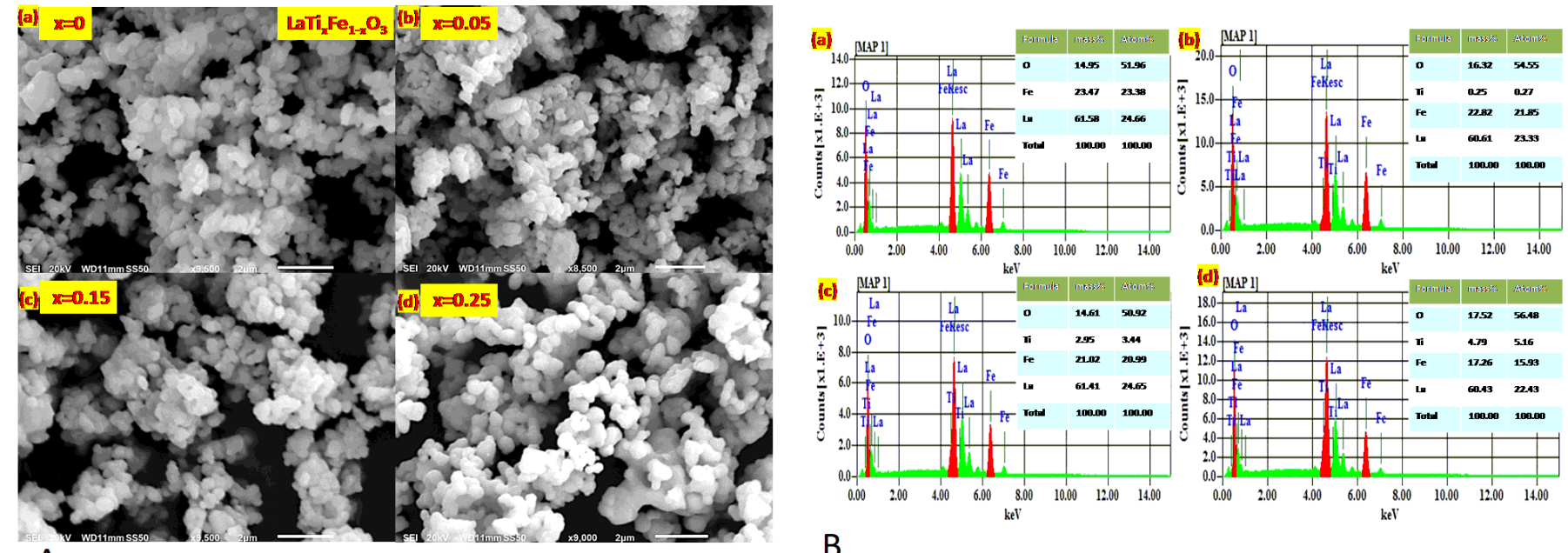

A.

B.

\section{Figure 5}

A.SEM images of synthesized LaTixFe1-xO3 $(x=0,0.05,0.15,0.25)(a-d)$ ferrite samples. B. Energy Dispersive X-ray (EDX) pattern of synthesized LaTixFe1-xO3 ( $x=0,0.05,0.15,0.25)(a-d)$ ferrite samples.
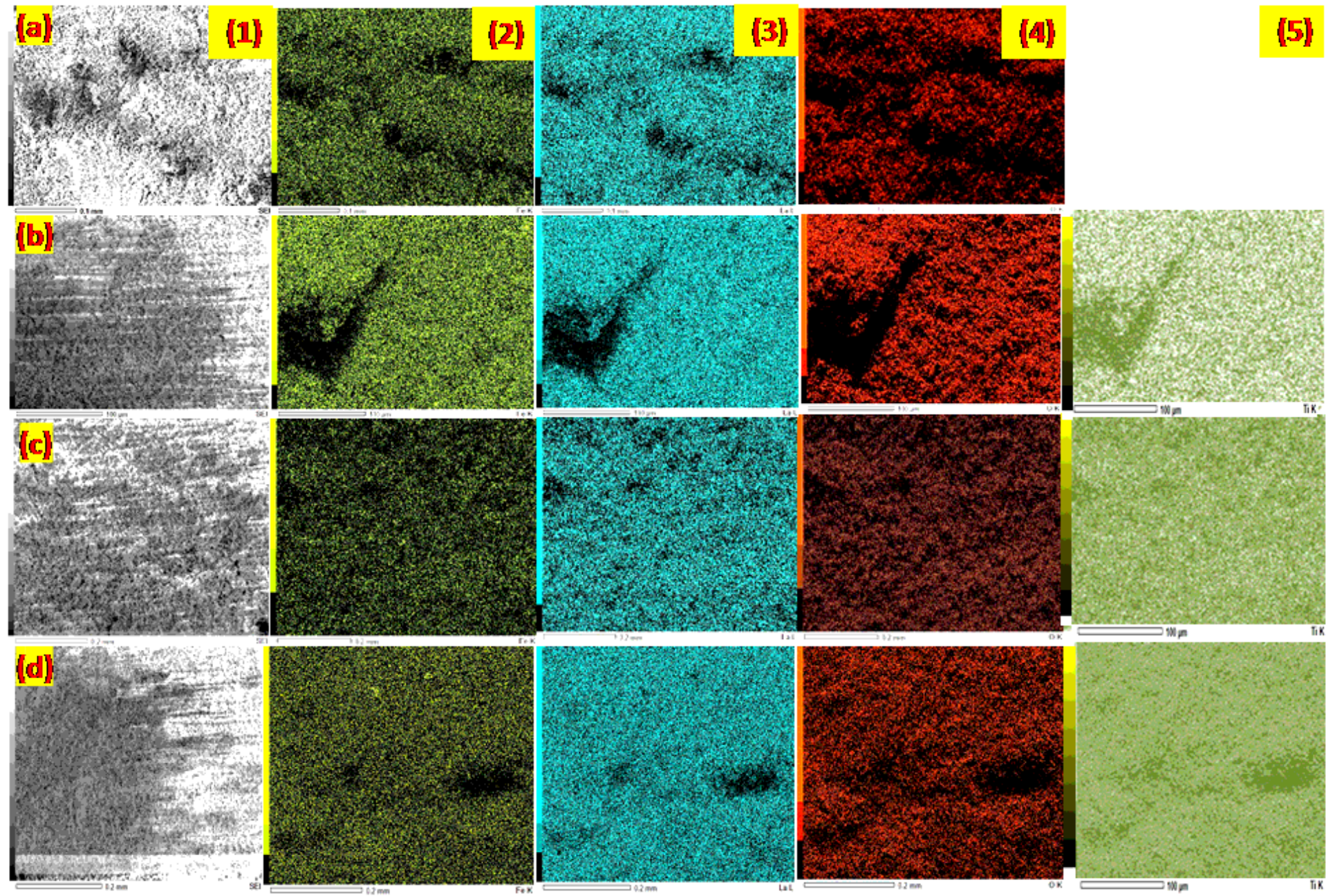

Figure 6 
Elemental mapping: column (1) the area of mapping, (2) iron distribution, (3) lanthanum distribution, (4) oxygen distribution, and (5) titanium distribution of the synthesized LaTixFe1-xO3, row wise (a) $x=0$, row (b) $x=0.05$, row (c) $x=0.15$, row (d) $x=0.25$, row of ferrite samples.

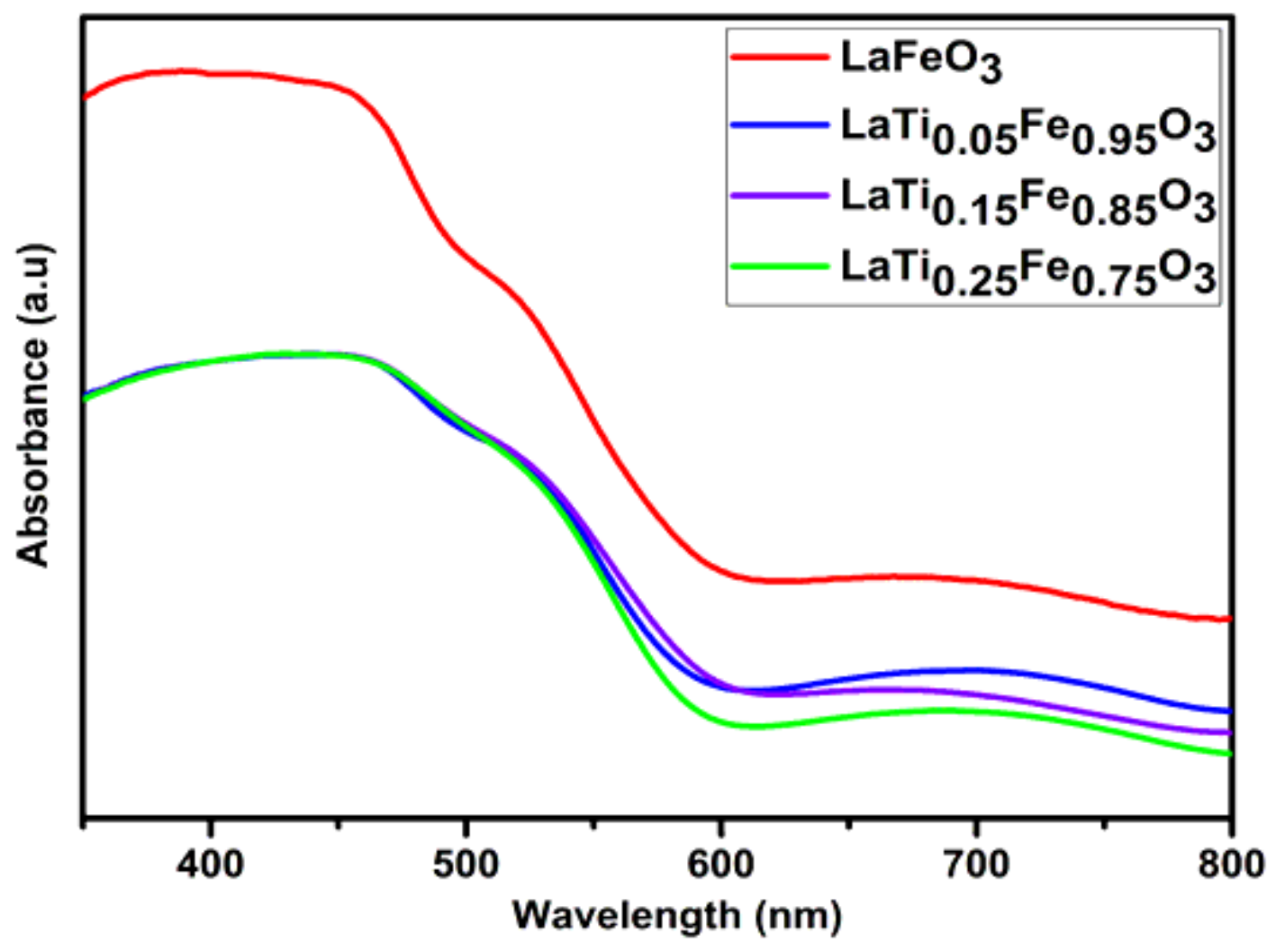

Figure 7

UV-Vis absorbance spectra of synthesized LaTixFe1-xO3 $(x=0,0.05,0.15,0.25)$ ferrite samples. 

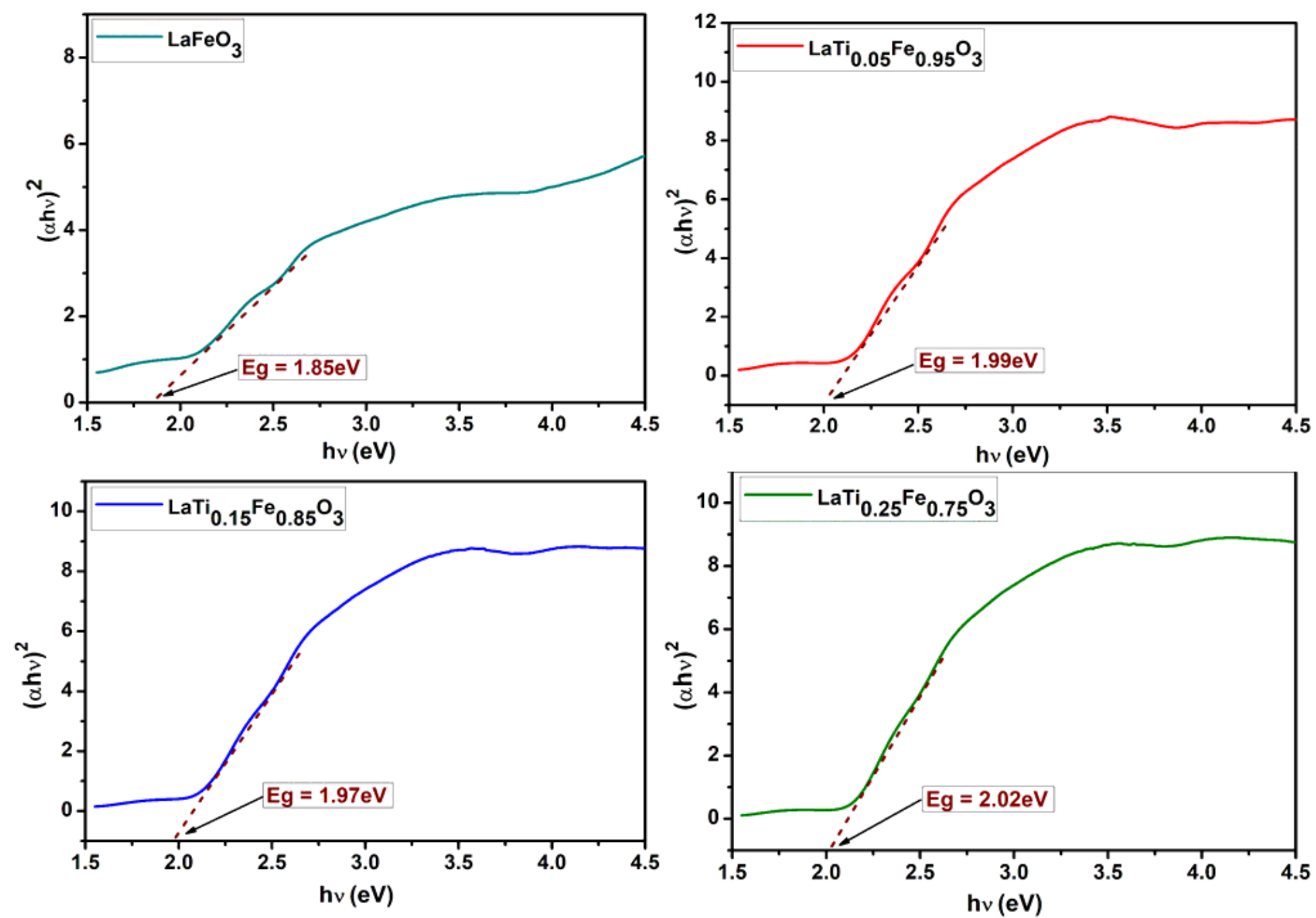

Figure 8

Tauc plots of (ahv)2 versus photon energy (hv) of synthesized LaTixFe1-xO3 ( $x=0,0.05,0.15,0.25)$ ferrite samples. 


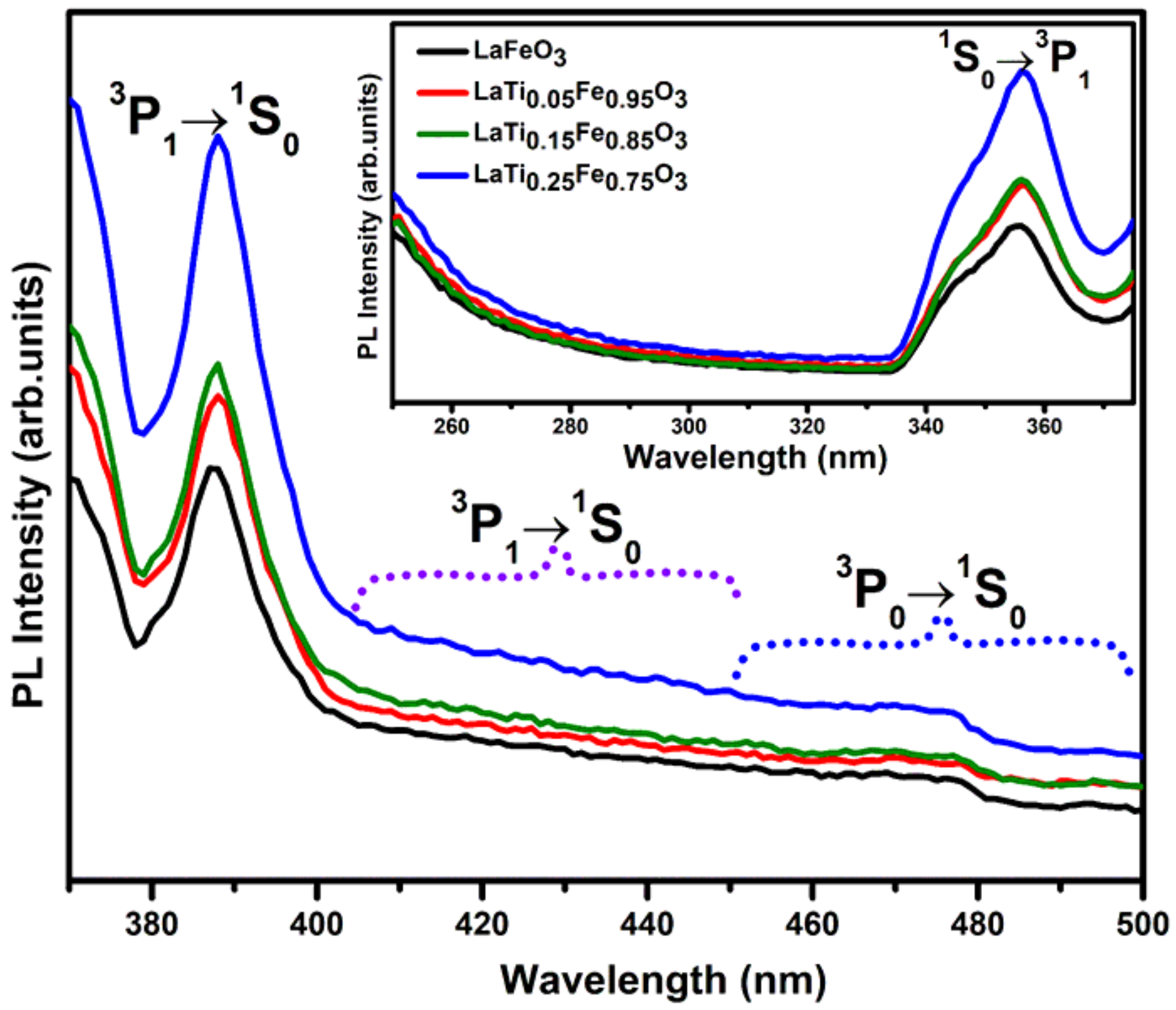

Figure 9

The photoluminescence excitation (inset) and emission spectra of LaTixFe1-xO3 ( $x=0,0.05,0.15,0.25)$ ceramic compounds. 


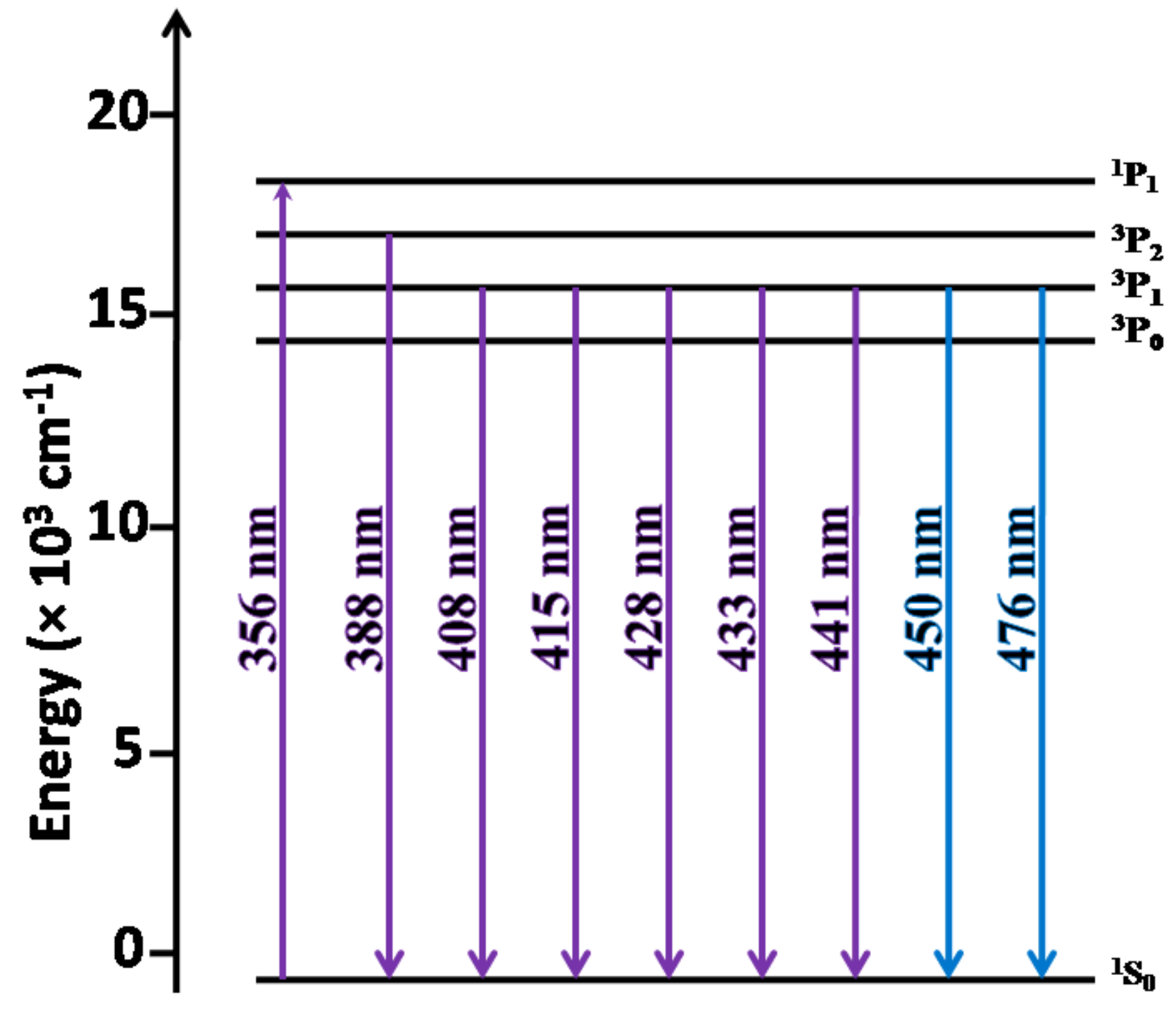

Figure 10

Schematic Energy level diagram of the optical transitions within LaTixFe1-xO3 $(x=0,0.05,0.15,0.25)$ derived from using the Rare Earth Handbook [37]. 

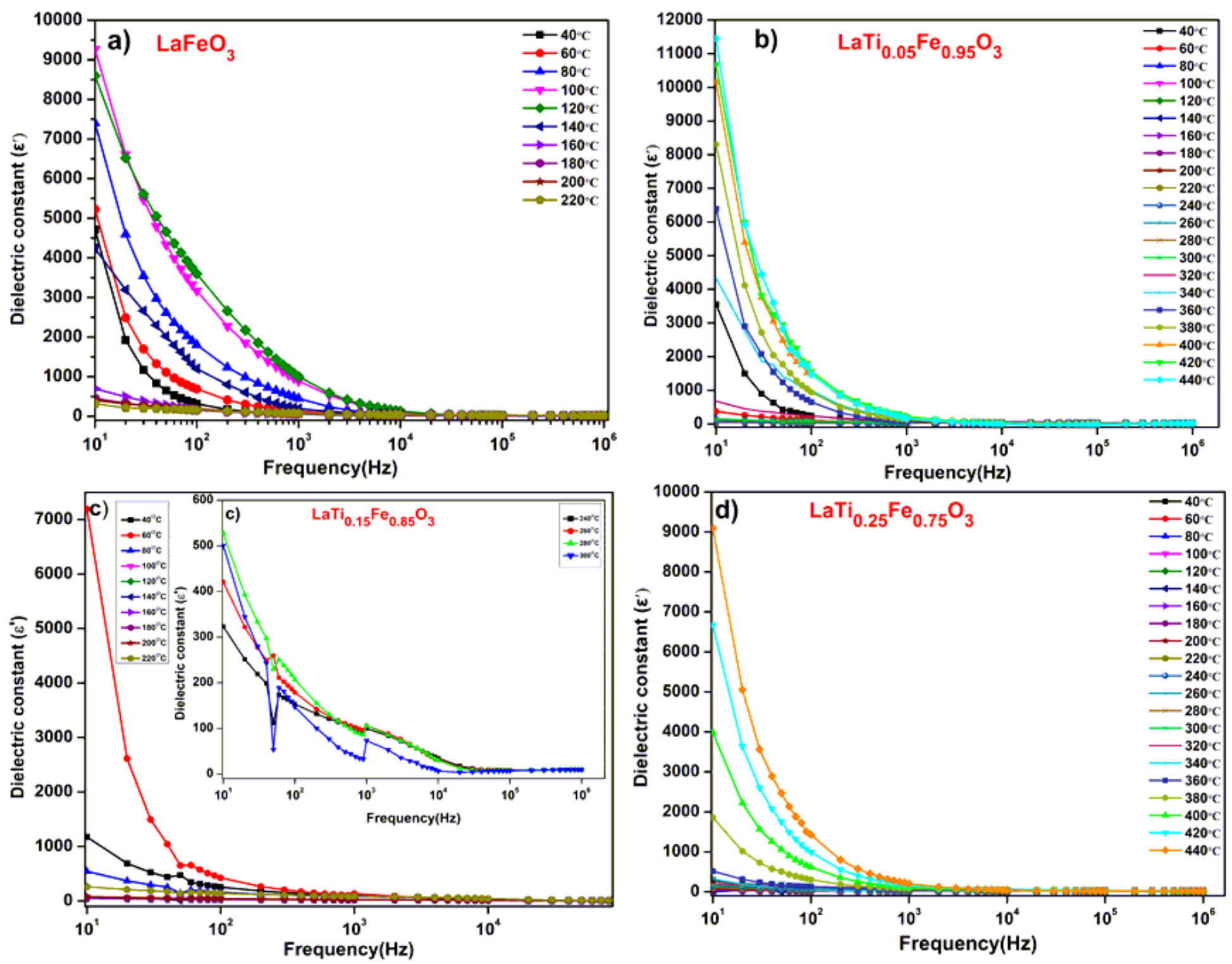

Figure 11

Frequency dependence of dielectric constant of the synthesized (a-d) LaTixFe1-xO3 $(x=0,0.05,0.15,0.25)$ samples. 

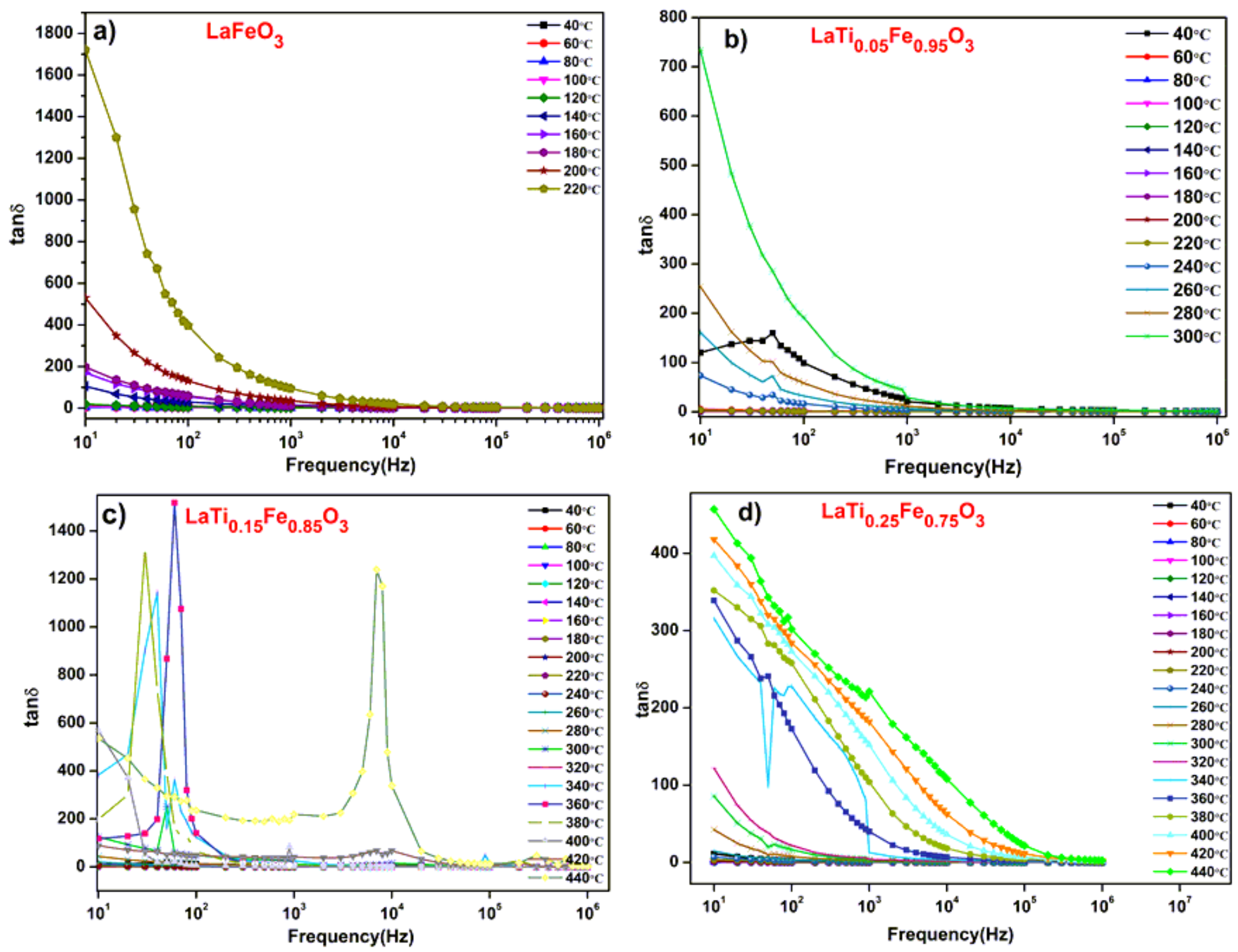

Figure 12

Frequency dependence of dielectric loss of the synthesized (a-d) LaTixFe1-xO3 $(x=0,0.05,0.15,0.25)$ samples. 

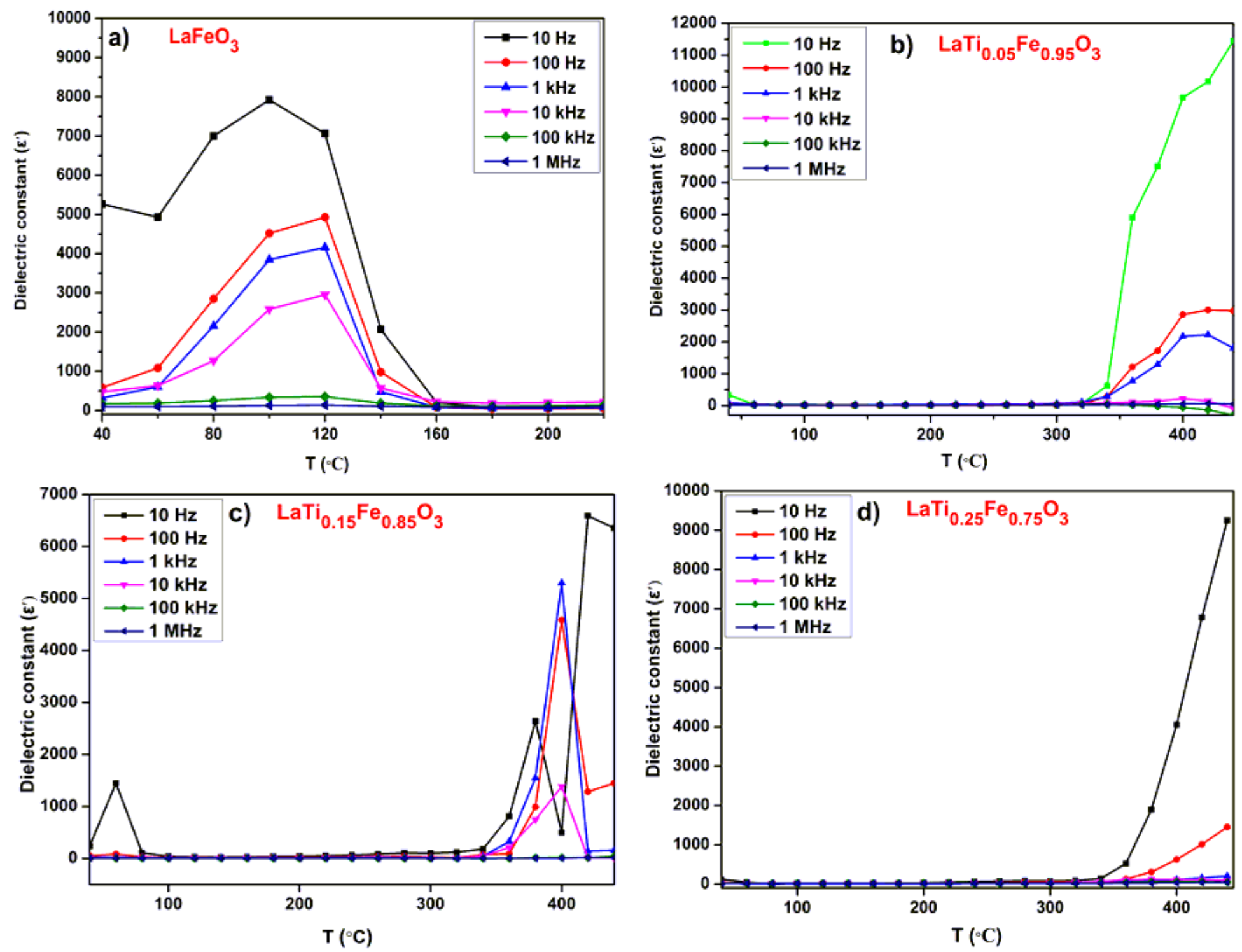

Figure 13

Temperature dependence of dielectric constant of the synthesized (a-d) LaTixFe1-xO3 $(x=0,0.05,0.15$, $0.25)$ samples. 

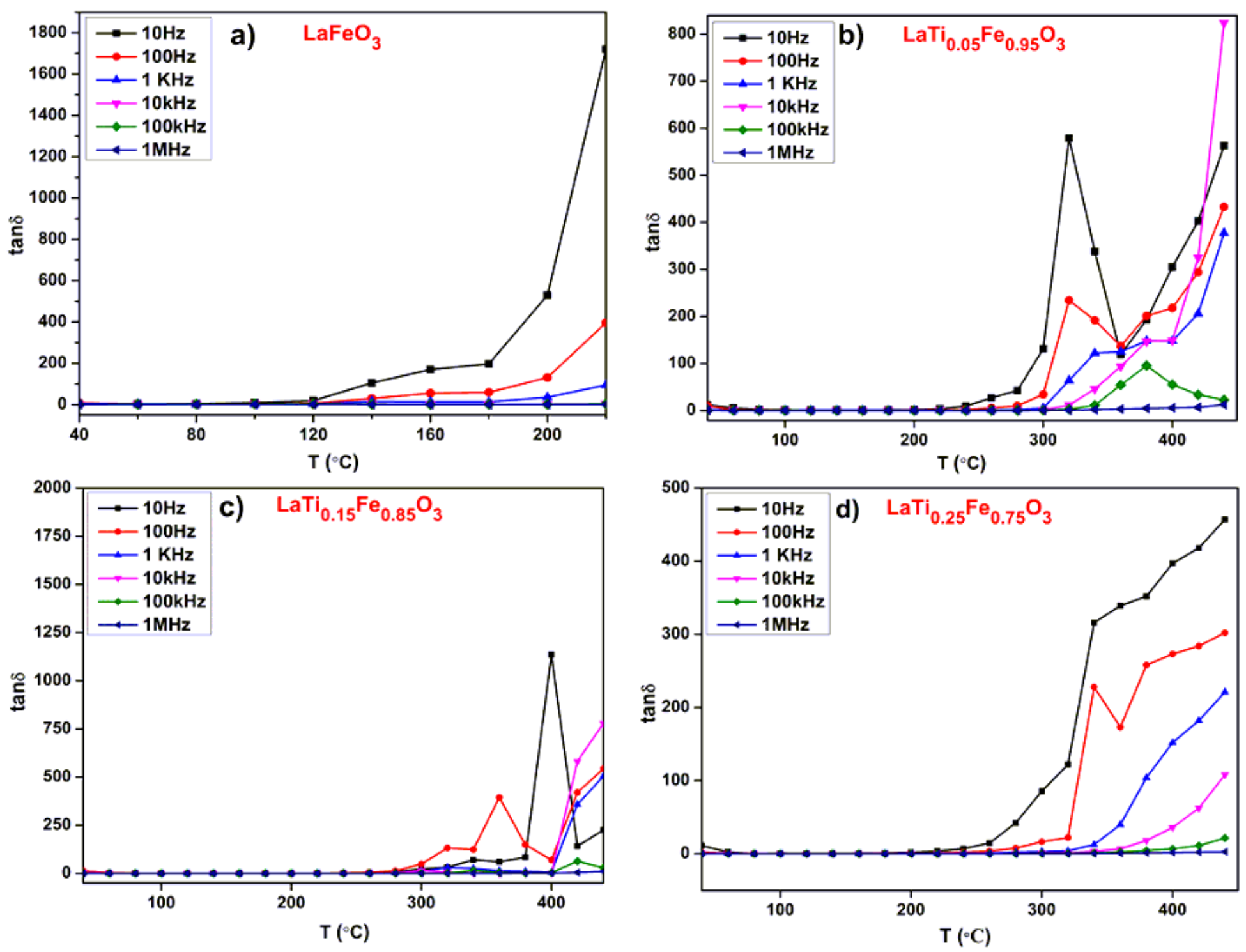

Figure 14

Temperature dependence of dielectric loss of the synthesized (a-d) LaTixFe1-xO3 $(x=0,0.05,0.15,0.25)$ samples. 

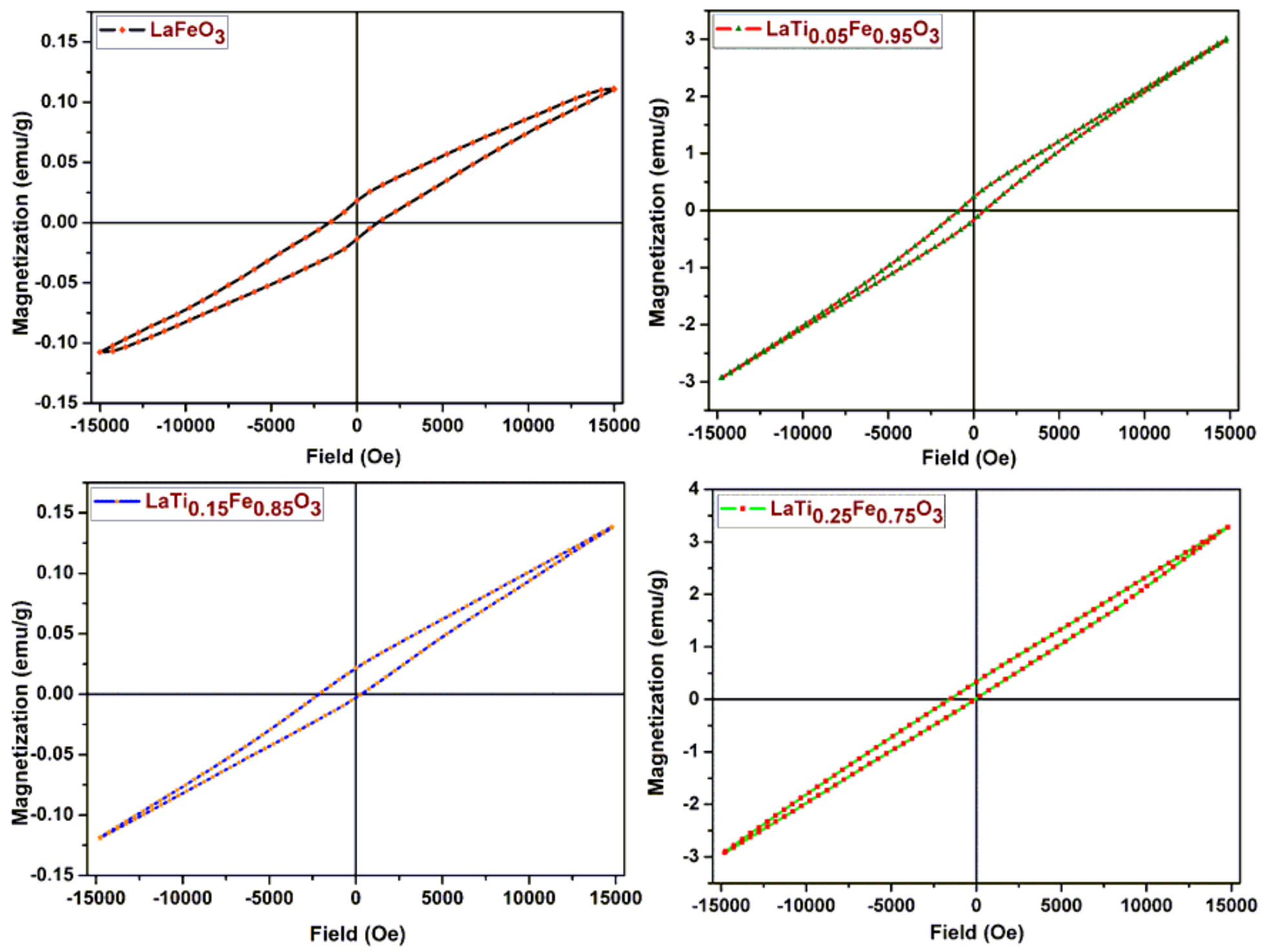

Figure 15

Hysteresis loops of synthesized LaTixFe1-xO3 $(x=0,0.05,0.15,0.25)$ ceramic compounds at room temperature. 